\title{
Surface Roughness Quality and Dimensional Accuracy-A Comprehensive Analysis of 100\% Infill Printed Parts Fabricated by a Personal/Desktop Cost-Effective FDM 3D Printer
}

\author{
Mohammad S. Alsoufi*, Abdulrhman E. Elsayed \\ Department of Mechanical Engineering, College of Engineering and Islamic Architecture, Umm Al-Qura University, \\ Makkah, KSA \\ Email: *mssoufi@uqu.edu.sa
}

How to cite this paper: Alsoufi, M.S. and Elsayed, A.E. (2018) Surface Roughness Quality and Dimensional Accuracy-A Comprehensive Analysis of 100\% Infill Printed Parts Fabricated by a Personal/Desktop CostEffective FDM 3D Printer. Materials Sciences and Applications, 9, 11-40.

https://doi.org/10.4236/msa.2018.91002

Received: November 27, 2017

Accepted: January 2, 2018

Published: January 5, 2018

Copyright (๑) 2018 by authors and Scientific Research Publishing Inc. This work is licensed under the Creative Commons Attribution International License (CC BY 4.0).

http://creativecommons.org/licenses/by/4.0/

(c) (i) Open Access

\begin{abstract}
Fused deposition modeling (FDM) has become widely used for personal/ desktop cost-effective printers. This work presents an investigational platform, which is used to study the surface roughness quality, and dimensional accuracy of $100 \%$ infill density printed parts fabricated by a personal/desktop cost-effective FDM 3D printer using different types of thermoplastic filament materials namely, PLA, PLA+, ABS and ABS+. Varieties of experiments were conducted after the fabricated parts were naturally cooled down for at least three hours to room temperature. During printing work, the nozzle diameter, layer height, nozzle temperature and printing speed were set at $0.3 \mathrm{~mm}, 0.1$ $\mathrm{mm}, 220^{\circ} \mathrm{C}$ and $30 \mathrm{~mm} / \mathrm{s}$, respectively. According to the experimentally obtained data results over $10 \mathrm{~mm}$ scanned profile and $90^{\circ}$ measuring direction (perpendicular to building direction), PLA+ thermoplastic filament material shows an excellent surface behaviour and is found to be more accurate while ABS does exhibit high surface roughness, waviness and primary behaviour. Both PLA and ABS+ show good surface performance.
\end{abstract}

\section{Keywords}

Additive Manufacturing (AM), Surface Roughness, Waviness, Primary, 3D

Prints, Fused Deposition Modeling (FDM)

\section{Introduction}

After almost 25 years of research in the field of rapid prototyping (RP) [1], it is 
still in its primary stages and various obstacles with this technology that still exist, however, it provides possible cost-effective production of high-end two-dimensional (2D) and three-dimensional (3D) products which are alternatives to traditional manufacturing technology and also it continues to grow with additional methods and applications [2]. Recently, 3D printing technology has gone beyond being an industrial prototyping and manufacturing process to become more accessible to small companies (i.e., start-up companies) and even individuals (i.e., personal/desktop 3D printers). Amongst the many RP technologies in the market share, the fused deposition modeling (FDM) method is considered as one of the additive manufacturing (AM) technologies that can automatically, precisely and economically fabricate any (unknown) physical three-dimensional (3D) solid objects from virtual computer-aided design (CAD) model data with even very complex geometrical shapes [3] [4]. It is used for design verification, medical modeling and rapid tooling applications [5]. The fabrication sequence is usually horizontal layer-by-layer or path-by-path in a relatively fast way in order to reduce the product development cycle period, without any tooling and/or fixture use [6]. The main advantages of AM technology include a good variety of thermoplastic polymer material available, easy material change, low maintenance cost, quick production of thin parts, absolute tolerance equal to or less than $\pm 0.1 \mathrm{~mm}$ overall, no need for supervision, no toxic materials, very compact size and variety of low-temperature operations [7]. Because of that, FDM 3D technique shows great potential in mould fabrication [8], biomedical device design [9], tissue engineering [10] and other industrial fields [11] [12] [13]. In contrast, the main drawbacks of AM technology are due to the fact that nozzle temperature fluctuations during the printing work could lead to high surface roughness and warping deformation particularly if compared to other traditional manufacturing technologies [7]. Thus, as RP is moving towards rapid manufacturing, there is increasing demand for obtaining high-quality surface roughness and dimensional accuracy in its printed parts as this has more influence on how the customers judge the quality of the final product.

\subsection{Modeling of the FDM 3D Surface Profile}

Fundamentally, FDM 3D technology is mainly based on the layer manufacturing process [14] and the fundamental principle is quite straightforward [15]. The personal/desktop cost-effective FDM 3D is mostly a layer-by-layer (one layer at a time) or path-by-path (one path at a time) following thermoplastic filament material deposition process to build functional 3D parts according to generated section data from a prepared 3D CAD model.

Figure 1 illustrates the manufacturing process and highlights some of the critical parts of the extrusion head as well as the deposition of the extruded filament for the FDM 3D printer. As can be seen from Figure 1, it shows a wireshaped engineering thermoplastic filament material, typically $2.85 \mathrm{~mm}$ or 1.7 $\mathrm{mm}$ in diameter, which is fed horizontally into a heated extruder (single-extruder) by motorized gantry driving force from a coil reel by a numerical 


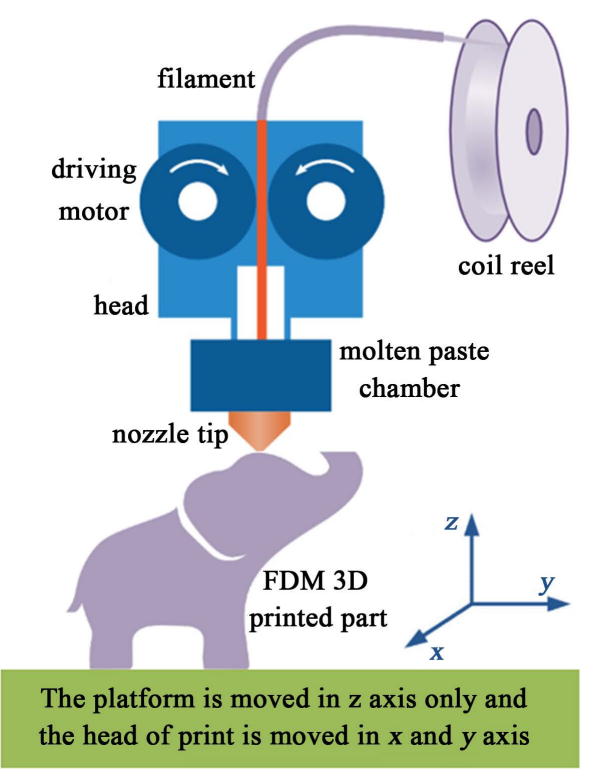

Figure 1. The manufacturing process to construct a physical model by FDM technique.

control system code to generate a prescribed pattern, and transferred into a molten paste (semi-liquid state and above its melting point) to be extruded from the circular nozzle die results in a cylindrical coiled morphology of each layer or path. The extruded thermoplastic filament material is squeezed on the print bed (usually a glass platform) line by line ( $\mathrm{x}$-y directions) based on the pre-designed tool paths to form a surface and finally the FDM 3D part from bottom to the top as with other RP technologies. After one layer has been completed, the extruder is lifted by a distance of layer thickness to deposit another layer and the process repeats for the next cross-sectioned layer until the 3D printed part is completed. Then, the thermoplastic filament material cools, solidifies within a tight time of roughly a few seconds (depending on the filament material) and then sticks to the surrounding material [16] [17]. For more details, see [18] [19].

Commercially, a variety of traditional feedstock thermoplastic filament materials are supported by FDM based 3D printers, which make them ideal for the consumer market, including acrylonitrile butadiene styrene (ABS) [20], polypropylene (PP) [15], polycarbonate (PC) [21], polylactic acid (PLA) [22], polyether imide (PEI) [23], short fiber composite [24], metal [25], bio-resorbable polymers [26], ceramic [27] and metal/polymers mixture materials [28].

The FDM method is perhaps the ultimate common 3D printing technique due to the number of FDM-based 3D printers available in the marketplace and indeed their low price (a cost of below \$2000). Clearly, the unique method of printing 3D structures could have enormous potential and competitive advantages over the traditional fabrication or manufacturing processes.

\subsection{Surface Roughness Measurement in AM}

Surface finish quality on RP is becoming more and more vital with more printed parts being used for end-user purposes. Surface finish quality is critical not only 
for better functionality and appearance but also for cost reduction regarding reduced post-processing of $3 \mathrm{D}$ printed parts and overall prototyping time reduction also.

So, in this paper, the surface roughness amplitude parameters, which are independent parameters of each other, were quantitatively measured off-line in micro-meter level from the filtered profiles at $90^{\circ}$ measuring direction across building direction. These amplitude parameters are average surface roughness, $R_{\mathrm{a}}$, root mean square, $R_{\mathrm{q}}$, skewness, $R_{\mathrm{sk}}$, and kurtosis, $R_{\mathrm{ku}}$. Other parameters such as height characterization $\left(R_{\mathrm{k}}, R_{\mathrm{pk}}, R_{\mathrm{vk}}, \mathrm{M}_{\mathrm{r} 1}\right.$ and $\left.\mathrm{M}_{\mathrm{r} 2}\right)$ using the linear material ratio curve ISO13565-21996 standard were also considered and measured quantitatively off-line at micro-meter level. Bear in mind that the surface roughness amplitude parameters were selected according to the recommendations in the literature review and under consideration of the data processing facilities available with differing levels of information [29] [30] [31] [32] [33]. These amplitude parameter definitions are listed in Table 1 [34] and they are the same independent manufacturing parameters which were used during this investigation.

There are various methods obtainable for measuring the surface roughness profile and they can be further divided into two main groups of 1) contact method and 2) non-contact method [35]. Here, all FDM 3D fabricated parts were measured using a contact-type Taly-Surf profilometer (Taylor Hobson Precision, Inc.). Every assessment condition was repeated at least three times at new locations on the FDM 3D printed parts surface in order to ensure reproducibility of the obtained results. Gaussian high-pass filter filtered the surface roughness profile with a cut-off length ${ }^{1}$ of $800 \mu \mathrm{m}$ and evaluation length was chosen to be five times the sampling length ${ }^{2}$. The obtained data were analyzed with Origin$\mathrm{Lab}^{\oplus}$ software.

Details of an engineering surface roughness measurement procedure have been already reported elsewhere [36]-[43] and are only briefly summarized here.

\subsection{Proposed Approach}

From the extensive literature survey, it can be revealed that several types of research have been investigated to reduce the surface roughness and warping deformation of industrial/professional FDM 3D printed parts by optimizing fabrication process parameters without a specific focus on personal/desktop cost-effective FDM 3D printers (cost below \$2000) [7] [45]-[51]. However, there are still some glaring shortcomings in the literature.

So, to overcome this gap, in this research paper, the authors have studied the variation of surface roughness and dimensional accuracy of printed parts produced by a personal/desktop cost-effective FDM 3D printer including different

${ }^{1}$ Cut-off length: This parameter is used in profile filters, determines which wavelengths belong to roughness and which ones to waviness. Only the roughness parts will be used to calculate the $R_{\mathrm{a}}, R_{\mathrm{q}}$, and so on.

${ }^{2}$ Sampling length: This is the reference length for roughness evaluation whose length is equal to the cut-off length. 
Table 1. Definition of surface roughness amplitude parameters, adapted from [34] [44].

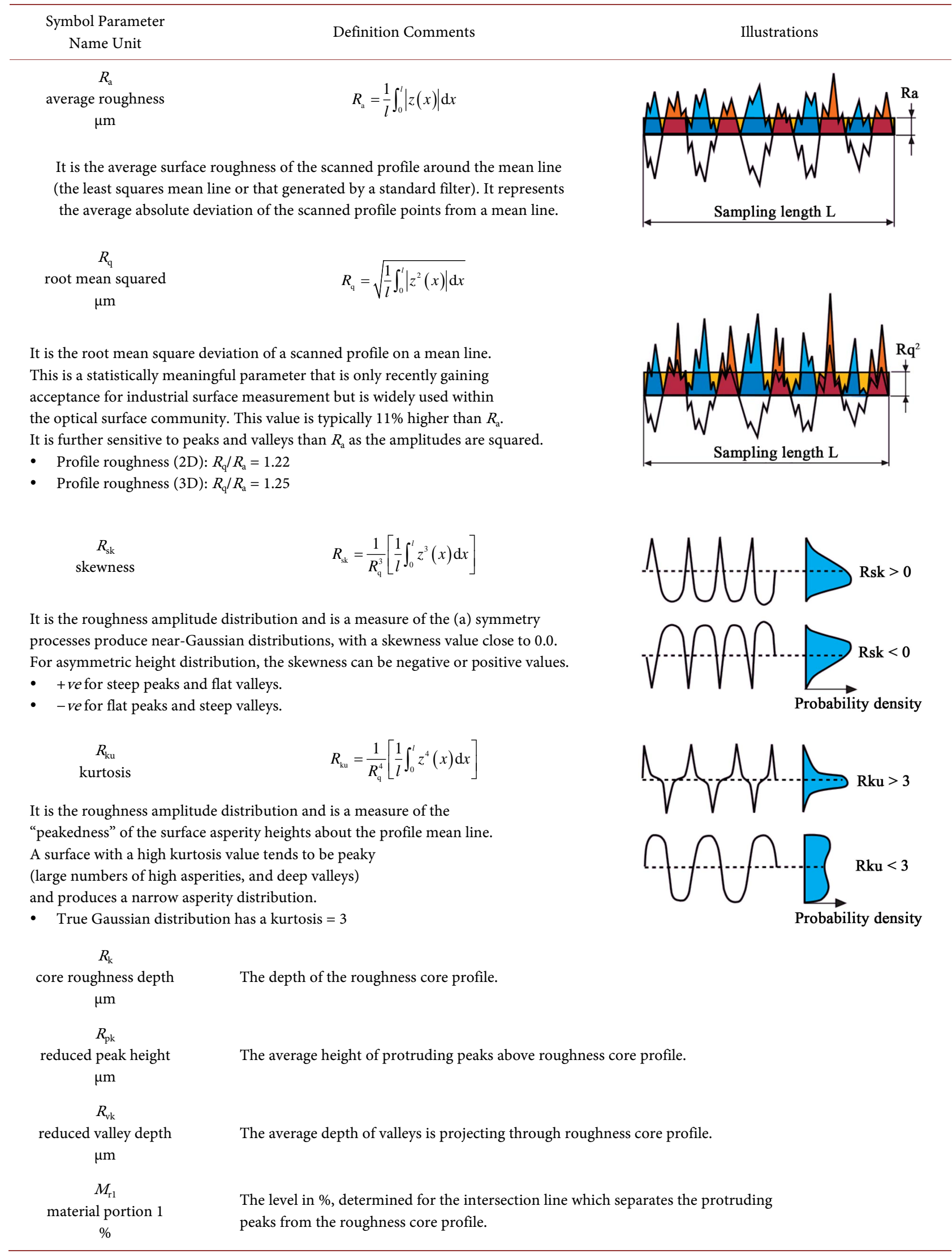




\section{Continued}

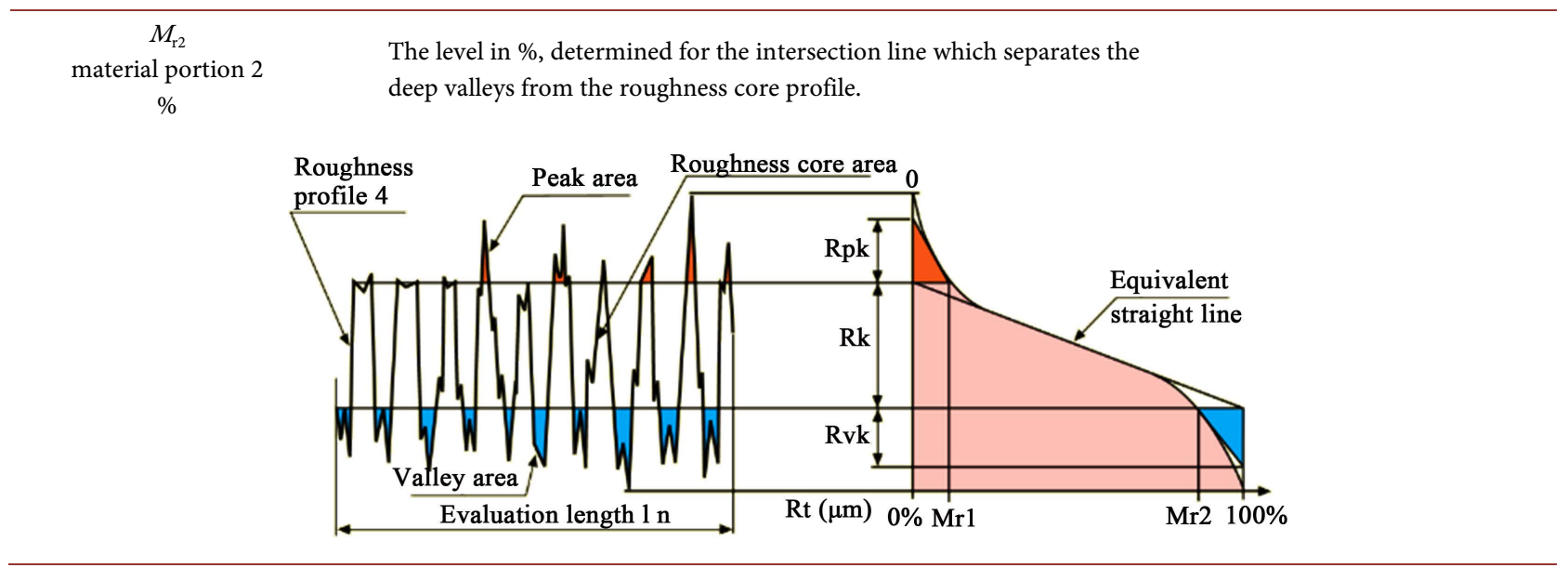

thermoplastic filament material as it is vital for determining the quality of the final product, and provides users with essential information on the tolerance of the personal/desktop cost-effective FDM 3D technology in additive manufacturing (AM) by commercial 3D printers. Besides, the acquired data will be assessed in such a way that they can be further employed in the design of the personal/desktop cost-effectives FDM 3D printed parts and thermoplastic filament materials development.

Figure 2 shows the workflow of the existing research paper. Similarly, to a great many other AM systems, the experiment started with a virtual 3D CAD modeling design that was prepared by using a conventional CATIA V5 3D solid modeling software tool in order to obtain the 3D proposed design. The 3D CAD model is then converted to STL (stereolithography or standard triangulated language) file format using CATIA software itself with a high level of control and precision. This file is used to create the cross-profile (mathematically slicing and orienting the model for the building process) that will be printed layer-by-layer (layers' outline) or path-by-path (paths' outline). Finally, the open source Slic3r version 1.3.0-dev software (G-code generator for 3D printer) is used to adjust the manufacturing process parameters, calculate the tool paths, infill density of each layer and also to control the heated printer extruder head of the personal/desktop cost-effective FDM 3D machine through its SD card port/USB port for the 3D part fabrication. The surface roughness quality and dimensional accuracy of all FDM 3D printed parts are obtained using contact-type surface roughness test-rig and electronic digital Vernier caliper gauge, respectively. The above process makes the design printable (i.e., able to be formed). All the measurements were performed between one and two days after $3 \mathrm{D}$ printing.

\section{Experimental Details}

In this section, the personal/desktop cost-effective FDM 3D printer, filament materials, conditions used in the production and 3D geometry of the printed parts are described in detail in the following sub-sections. 


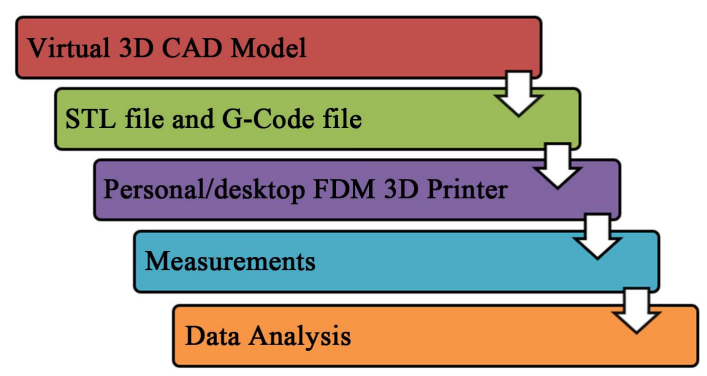

Figure 2. Experimental process flow chart.

\subsection{FDM 3D Printer and Materials}

The personal/desktop cost-effective FDM 3D printing machine used in this work is the BEAST from Cultivate3D, Australia (see previously published work for essential technical details, e.g., [18]). The personal/desktop cost-effective FDM 3D printing machine has the provision to vary all manufacturing process parameters. For the open-source, the thermoplastic filament material used for fabrication parts was PLA, PLA+, ABS and ABS+ in order to evaluate the performance of the surface roughness quality and dimensional accuracy. These thermoplastic filament materials are particularly suitable for industrial applications since they are easily manageable in their pre-fusion state at low temperatures, steadily harden as they cool down at glass transition temperature and revert back to their initial properties [52]. The thermoplastic filament materials used during this investigation was supplied by Shenzhen Esun Industrial Co., Ltd.

Polylactic acid (PLA) is bio-degradable thermoplastic aliphatic polyester with molecular formula $\left(\mathrm{C}_{3} \mathrm{H}_{4} \mathrm{O}_{2}\right)_{n}$ derived from renewable resources and manufactured out of plant-based materials, whereas reinforced polylactic acid (PLA+) is advanced and optimized thermoplastic filament material with toughness which is ten times more than the PLA on the market. On the other hand, acrylonitrile butadiene styrene $(\mathrm{ABS})$ is also a thermoplastic material with molecular formula $\left(\mathrm{C}_{8} \mathrm{H}_{8} \cdot \mathrm{C}_{4} \mathrm{H}_{6} \cdot \mathrm{C}_{3} \mathrm{H}_{3} \mathrm{~N}\right)_{\mathrm{n}}$ and its proportions may vary from $15 \%$ to $35 \%$ (acrylonitrile, "A") $5 \%$ to $30 \%$ (butadiene, " $\mathrm{B}$ ") and $40 \%$ to $60 \%$ (styrene, "S") and it is manufactured out of oil-based materials, whereas reinforced acrylonitrile butadiene styrene (ABS+) is advanced and optimized thermoplastic filament material with high toughness, hardness and rigidity, excellent scratch resistance, excellent oil resistance and excellent heat resistance. All four types of thermoplastic filament materials with $1.75 \mathrm{~mm}$ diameter have a ranging accuracy of 1.7 to $1.8 \mathrm{~mm}$ [53]. Table 2 shows the 3D printing filament specifications.

\subsection{Parameters Selection}

Many fabrication parameters have impacts on the surface quality of FDM 3D printed parts, for example, layer height, nozzle diameter, printing speed, raster angle, shell thickness and infill density and so on. Moreover, different factors make diverse influences on the surface quality and dimensional accuracy of the printed parts. The major ones are layer height and nozzle diameter. The thin 
Table 2. 3D printing filament specifications, adapted from [54].

\begin{tabular}{|c|c|c|c|c|}
\hline \multirow{2}{*}{$\begin{array}{c}\text { Parameters } \\
\text { Material }\end{array}$} & \multicolumn{4}{|c|}{ Sample Group } \\
\hline & PLA & PLA+ & ABS & $\mathrm{ABS}+$ \\
\hline Colour & Glass Blue & Silver & Brown & White \\
\hline Print temperature $\left({ }^{\circ} \mathrm{C}\right)$ & $190-210$ & $205-225$ & $220-260$ & $220-260$ \\
\hline Bed temperature $\left({ }^{\circ} \mathrm{C}\right)$ & No heat $(60-80)$ & No heat $(60-80)$ & 110 & 110 \\
\hline Distortion temperature $\left({ }^{\circ} \mathrm{C}, 0.45 \mathrm{MPa}\right)$ & 56 & 52 & 78 & 73 \\
\hline Melt flow index (g/10mln) & $5\left(190^{\circ} \mathrm{C} / 2.16 \mathrm{Kg}\right)$ & $2\left(190^{\circ} \mathrm{C} / 2.16 \mathrm{Kg}\right)$ & $12\left(220^{\circ} \mathrm{C} / 10 \mathrm{Kg}\right)$ & $15\left(220^{\circ} \mathrm{C} / 10 \mathrm{Kg}\right)$ \\
\hline Tensile strength (MPa) & 65 & 60 & 43 & 40 \\
\hline Elongation at break (\%) & 8 & 29 & 22 & 30 \\
\hline Flexural modulus (MPa) & 3600 & 3642 & 2348 & 2443 \\
\hline IZOD impact strength $\left(\mathrm{KJ} / \mathrm{m}^{2}\right)$ & 4 & 7 & 19 & 42 \\
\hline
\end{tabular}

layer produces a smoother surface than the thick layer, whether it is measured diagonally across building direction, perpendicular to building direction or parallel to building direction. Surface roughness and part deposition time seem always to contradict each other. It is the same with nozzle diameter.

In this paper, based on the previous research [18] [19], the sample manufactured details are listed in Table 3, including the main printing factors as mentioned before, and other factors are maintained at their default levels. This study has considered new thermoplastic filament materials and different infill density percentage. Infill percentage indicates how full or hollow the printed part is where $1 \%$ is the vertical shell and $100 \%$ is solid. It also severely influences the mechanical properties such as toughness. The printing speed controls how fast the nozzle of the 3D printer moves while extruding the heated filament, whereas the extrusion temperature controls the temperature of the extruding nozzle. The layer height controls the thickness of each layer. Finally, the infill patterns control how the nozzle fills and raster across the infill layers. Usually, the default layer thickness is $0.2 \mathrm{~mm}$ which gives decent prints. However, in this paper, for high-quality prints and low warping deformation, the layer thickness of $0.1 \mathrm{~mm}$ may be used, which is twice that of $0.2 \mathrm{~mm}$, but at the overall cost of building time.

\subsection{FDM 3D Geometry}

Several FDM 3D printed parts were manufactured with different thermoplastic filament materials (e.g., PLA, PLA+, ABS and ABS+) in order to measure the surface roughness quality and warping deformation. The chosen materials are the most relevant for each additive manufacturing (AM) process. All thermoplastic filament materials are provided by the manufacture of AM machines used. The dimensions of the very simple rectangular shape test specimen are $40 \mathrm{~mm} \times$ $40 \mathrm{~mm} \times 15 \mathrm{~mm}$ (length, width and height, respectively). 
Table 3. Summary of sample's technical properties and process parameters.

\begin{tabular}{|c|c|c|c|c|}
\hline \multirow{2}{*}{ Parameters } & \multicolumn{4}{|c|}{ Sample Group } \\
\hline & A & B & $\mathrm{C}$ & $\mathrm{D}$ \\
\hline No. of samples & 1 & 1 & 1 & 1 \\
\hline Material & PLA & PLA+ & ABS & $\mathrm{ABS}+$ \\
\hline Colour & Glass Blue & Silver & Brown & White \\
\hline Average weight (g) & 19.2013 & 20.5155 & 10.2642 & 16.1946 \\
\hline AM process & \multicolumn{4}{|c|}{ FDM (Fused Deposition Modeling) } \\
\hline Layer height $(\mathrm{mm})$ & \multicolumn{4}{|c|}{0.1} \\
\hline Infill density (\%) & \multicolumn{4}{|c|}{100} \\
\hline Nozzle diameter $(\mathrm{mm})$ & \multicolumn{4}{|c|}{0.3} \\
\hline Nozzle temperature $\left({ }^{\circ} \mathrm{C}\right)$ & \multicolumn{4}{|c|}{220} \\
\hline Printing speed $(\mathrm{mm} / \mathrm{s})$ & \multicolumn{4}{|c|}{30} \\
\hline Extrude of material (layer width) (mm) & \multicolumn{4}{|c|}{0.36} \\
\hline Speed for non-print moves (mm) & \multicolumn{4}{|c|}{60} \\
\hline Vertical shells & \multicolumn{4}{|c|}{1} \\
\hline Cooling rate & \multicolumn{4}{|c|}{ Built-in } \\
\hline Bed temperature $\left({ }^{\circ} \mathrm{C}\right)$ & \multicolumn{4}{|c|}{ Room temperature } \\
\hline Room temperature $\left({ }^{\circ} \mathrm{C}\right)$ & \multicolumn{4}{|c|}{$25 \pm 1$} \\
\hline Relative humidity (\% RH) & \multicolumn{4}{|c|}{$40 \pm 5$} \\
\hline
\end{tabular}

Figure 3 shows the rectangular sample details and the measuring direction. Bear in mind that the $90^{\circ}$ measuring direction is perpendicular to the building direction for all 4 -identical faces, whereas at the top face (middle), the $\pm 45^{\circ}$ measuring direction is perpendicular to $\pm 45^{\circ}$ raster angle flat orientation.

\subsection{FDM 3D Printed Print}

A personal/desktop cost-effective FDM 3D printer (cost below \$2000) was used to fabricate the parts using four different thermoplastic filament materials namely PLA, PLA+, ABS and ABS+. All thermoplastic filament materials are $1.70 \mathrm{~mm}$ in diameter and enter into the extruder in which it is fused at $220^{\circ} \mathrm{C}$. The pressure of the feeding system causes the extrusion, changing in the filament material diameter from $1.70 \mathrm{~mm}$ to $0.48 \mathrm{~mm}$ (layer width). The thermoplastic filament material is ejected through the circular nozzle $(0.3 \mathrm{~mm})$, and finally deposited in layers onto a glass platform that underneath has no heated bed. Four different FDM 3D printed parts were chosen for the final assessment as shown in Figure 4. Besides, the double-sided thermal epoxy resin adhesive was implemented between the first layer and the printing area of printing platform in order to reduce or even eliminate the warping deformation at each corner ( $\mathrm{C} 1, \mathrm{C} 2, \mathrm{C} 3, \mathrm{C} 4)$ and at each face (C1-C2, C2-C3, C3-C4, C4-C1, top). The FDM 3D geometrical part was $40 \mathrm{~mm}(\mathrm{~L}) \times 40 \mathrm{~mm}(\mathrm{~W}) \times 15 \mathrm{~mm}(\mathrm{H})$. Samples 


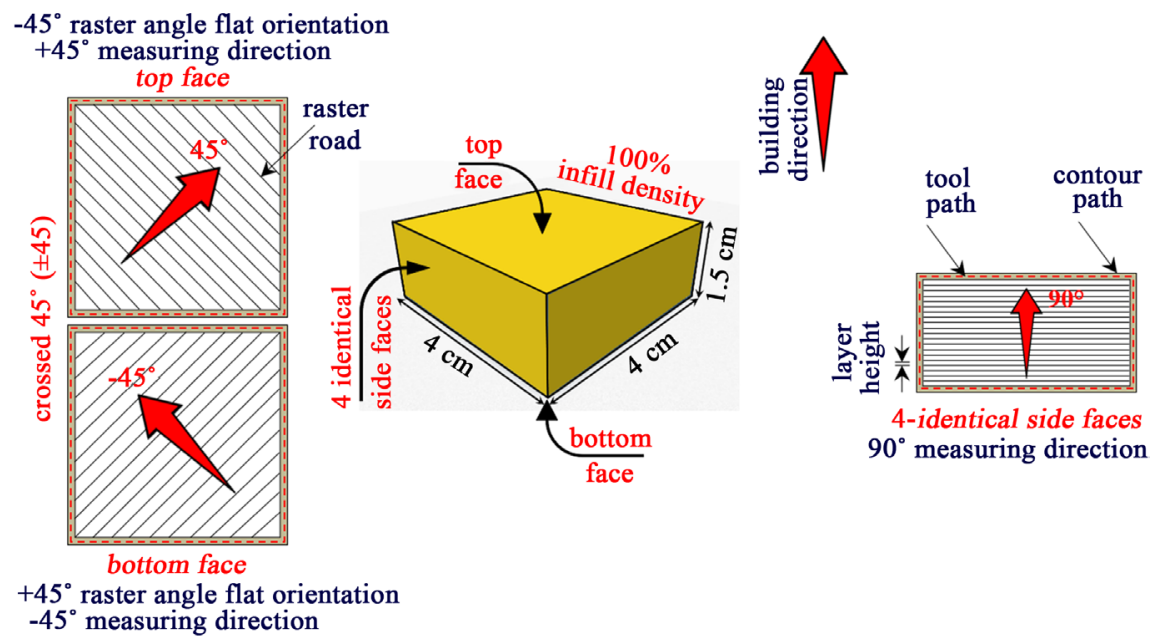

Figure 3. Proposed FDM 3D printed part, filament deposition patterns and measuring direction.

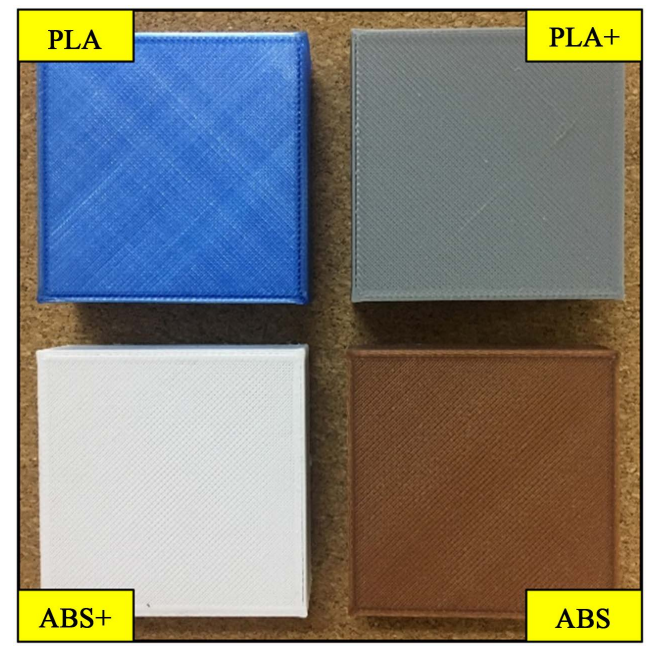

Figure 4. FDM 3D printed parts using different filament material.

of different filament materials were printed with a raster road of $+45 /-45$ (diamond), 0/90 flat build orientation and $100 \%$ infill density pattern shape. The build time was recorded from the printing screen status on the machine itself. Besides, all the FDM 3D specimens were weighed by using a precision weighing balance named Sartorius 1702, model CP224S in a temperature and humidity controlled metrology laboratory, generally at $20^{\circ} \mathrm{C} \pm 1{ }^{\circ} \mathrm{C}$ and $40 \% \pm 5 \%$ relative humidity. The surface roughness and dimensional accuracy of the FDM 3D printed parts were obtained by using a contact-type surface profilometer test-rig and electronic digital Vernier caliper gauge, respectively.

\section{Results and Discussion}

The surface roughness was measured in an angular position of $90^{\circ}$ (perpendicular to the building direction) at 4-identical faces and it was measured in an angular position of $\pm 45^{\circ}$ (perpendicular to $\pm 45^{\circ}$ raster angle flat orientation) at the 
top face. To measure the surface roughness of the test specimen, at least three readings were taken at a different location from each side $(\mathrm{C} 1-\mathrm{C} 2, \mathrm{C} 2-\mathrm{C} 3$, C3-C4, C4-C1) along with top side as shown in Figure 5(a) (method No. 1), while to measure the dimensional variation, at least ten readings were taken at a different location from each side (C1-C2, C2-C3, C3-C4, C4-C1) along with top side and each corner $(\mathrm{C} 1, \mathrm{C} 2, \mathrm{C} 3, \mathrm{C} 4)$ of the printed samples as shown in Figure 5(b) (method No. 2). The observed results are obtained and calculated based on the data generated from this paper in the following sub-section.

\subsection{Dimensional Accuracy Assessments}

Geometrical accuracy can be measured using an electronic digital Vernier caliper gauge and calculation of the deviation relative to the original STL file format. Figure 6 shows the dimensional accuracy of all printed parts. The FDM 3D printed parts show some differences in the dimensional accuracy of the actual values of $40 \mathrm{~mm}(\mathrm{~L}) \times 40 \mathrm{~mm}(\mathrm{~W}) \times 15 \mathrm{~mm}(\mathrm{H})$.

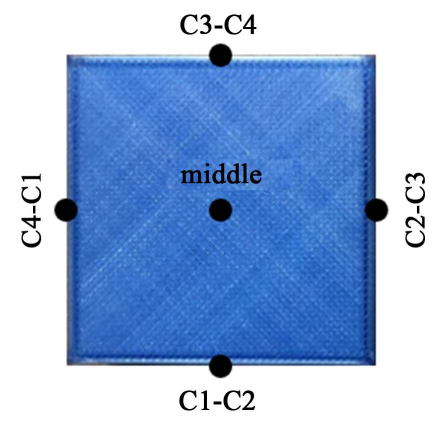

(a)

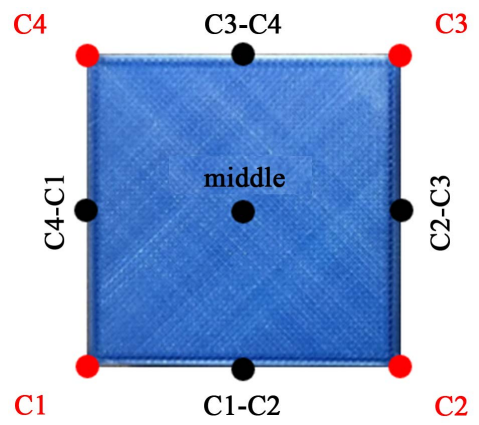

(b)

Figure 5. Measurement location on each printed part (a) method one and (b) method two.

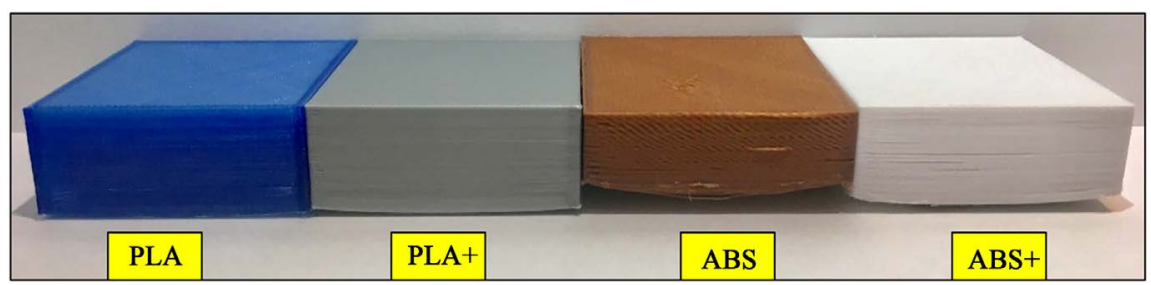

Figure 6. Printed parts with different filament materials. 
Figure 7 shows the dimensional variation between the original STL file format and printed parts in length, height and width. As can be seen, in the case of manufacturing $\mathrm{ABS}$ and $\mathrm{ABS}+$ thermoplastic using an FDM-based 3D printer, undesirable warping deformation and shape errors occur in the final rectangular samples due to heat shrinkage. ABS thermoplastic filament material shows the highest warping deformation in the height axis of almost $12.46 \pm 1.62 \mathrm{~mm}$ $(16.95 \% \pm 10.78 \%$, shape error) especially at corner 2 (C2) of almost $9.97 \mathrm{~mm}$ with 33.53\% shape error. Reinforced ABS+ shows some improvement with the same independent variables, but still some warping variation in the height exists

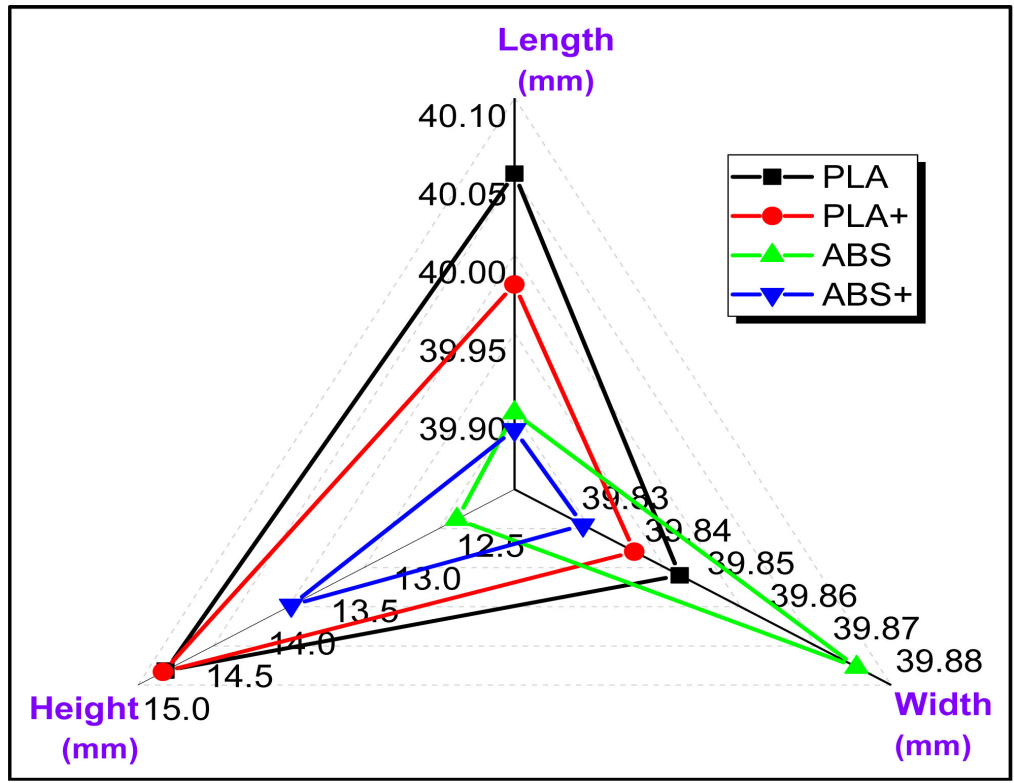

(a)

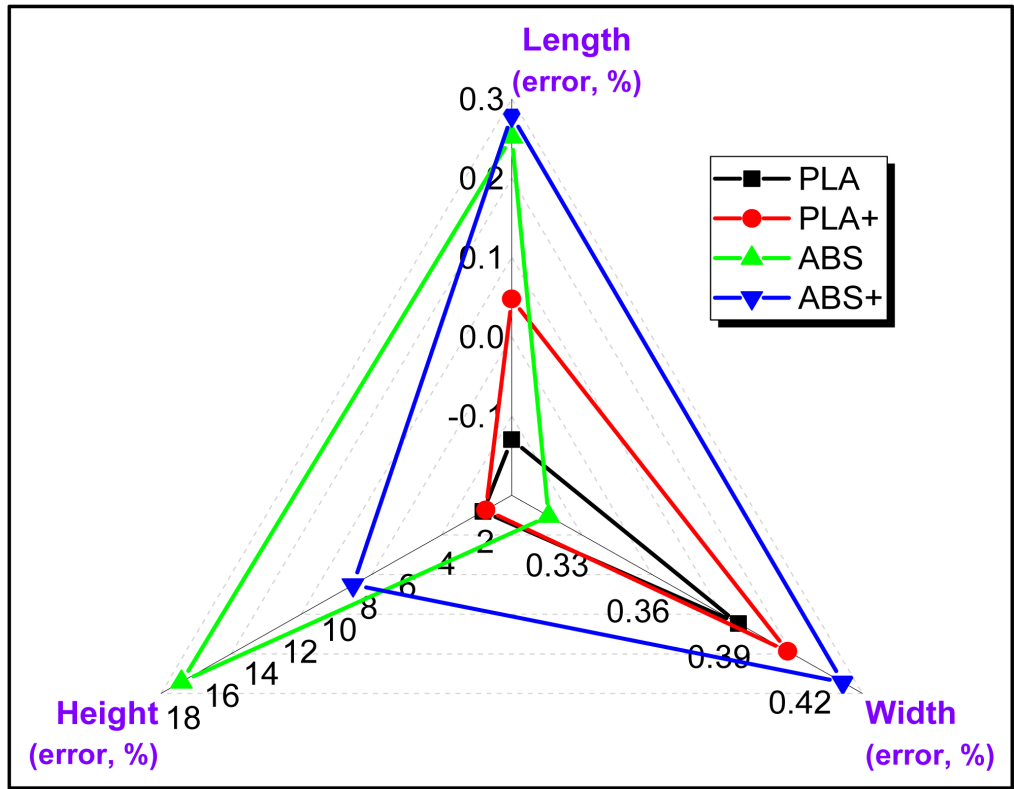

(b)

Figure 7. Dimensional variation represented as (a) mm variation and (b) error variation. 
of $13.78 \pm 0.74 \mathrm{~mm}(8.14 \% \pm 4.92 \%$, shape error $)$ especially at corner 3 (C3) by almost $12.51 \mathrm{~mm}$ with $16.60 \%$ shape error. It can be seen clearly that the error was reduced by almost $50 \%$ from $\mathrm{ABS}$ to $\mathrm{ABS}+$ with that same manufacturing process parameters including $220^{\circ} \mathrm{C}$ nozzle temperature. On the other hand, for both PLA and PLA+ thermoplastic filament materials which were used to print two rectangular $100 \%$ infill density, represent the lowest warping deformation of mean and standard deviation by almost $14.78 \pm 0.26 \mathrm{~mm}(1.47 \% \pm 1.71 \%$, shape error) and $14.80 \pm 0.22 \mathrm{~mm}(1.33 \% \pm 1.50 \%$, shape error $)$, respectively.

For the length and width variation compared to the true value of $40 \mathrm{~mm}$ in both axis in the original STL file, PLA+ shows a very small variation of almost $39.98 \pm 0.16 \mathrm{~mm}(0.05 \% \pm 0.40 \%$, shape error $)$ and $39.84 \pm 0.12 \mathrm{~mm}(0.40 \% \pm$ $0.30 \%$, shape error), respectively, followed by PLA, ABS and ABS+. For PLA, the length variation was $40.05 \pm 0.14 \mathrm{~mm}$ with total shape error of $-0.13 \% \pm 0.36 \%$ and the width variation was $39.85 \pm 0.11 \mathrm{~mm}$ with total shape error of $0.38 \% \pm$ $0.28 \%$. For ABS, the length variation was $39.90 \pm 0.09 \mathrm{~mm}$ with total shape error of $0.25 \% \pm 0.23 \%$ and the width variation was $39.87 \pm 0.04 \mathrm{~mm}$ with total shape error of $0.31 \% \pm 0.10 \%$. Surprisingly, reinforced ABS+ shows more variation in length and width than standard ABS by almost $39.89 \pm 0.28 \mathrm{~mm}$ with total shape error of $0.28 \% \pm 0.22 \%$ and by almost $39.835 \pm 0.11 \mathrm{~mm}$ with total shape error of $0.42 \% \pm 0.27 \%$, respectively. This variation in length, width and height might be due to the nozzle temperature of $220^{\circ} \mathrm{C}$ which is constant for all thermoplastic filament materials. For the group of PLA and PLA+, the selected nozzle temperature parameter of $220^{\circ} \mathrm{C}$ represented the maximum print temperature whereas for the group of $\mathrm{ABS}$ and $\mathrm{ABS}+$ it represented the minimum print temperature as recommended by the supplier (see Table 2). This two-boarded line between the maximum and minimum value of printed parts plays a significant role in the dimensional accuracy of all printed parts.

Figure 8 shows in detail the height geometry variation at a specific point of each face and corner (C1, C1-C2, C2, C2-C3, C3, C3-C4, C4, C4-C1, top). As can be seen, PLA and PLA+ show normal distribution variation on each face and corner whereas $\mathrm{ABS}$ and $\mathrm{ABS}+$ show non-uniform distribution on each face and corner under the same independent manufacturing process parameters. This fluctuation appears significantly in the face (C3-C4) and corner (C1). For PLA+, the maximum highest (warping deformation) appears on the top face (middle) by almost $15.21 \mathrm{~mm}$ which in divert from the true value by almost $-1.40 \%$ (surplus) and the minimum highest (warping deformation) appears in the corner (C3) by almost $14.4 \mathrm{~mm}$ with $4.00 \%$ shape error. For PLA, the maximum highest (warping deformation) appears in the face (C2-C3) by $15.00 \mathrm{~mm}$ with $100 \%$ level of confidence and the minimum highest (warping deformation) appears in the corner (C3) by roughly $14.55 \mathrm{~mm}$ with $3.00 \%$ shape error. The ABS and ABS+ thermoplastic filament material shows unpredicted highest variation between corners and faces ranging from $9.97 \mathrm{~mm}$ with $33.53 \%$ shape error at corner (C2) to $14.92 \mathrm{~mm}$ with $0.53 \%$ shape error at middle face and ranging from $12.51 \mathrm{~mm}$ 


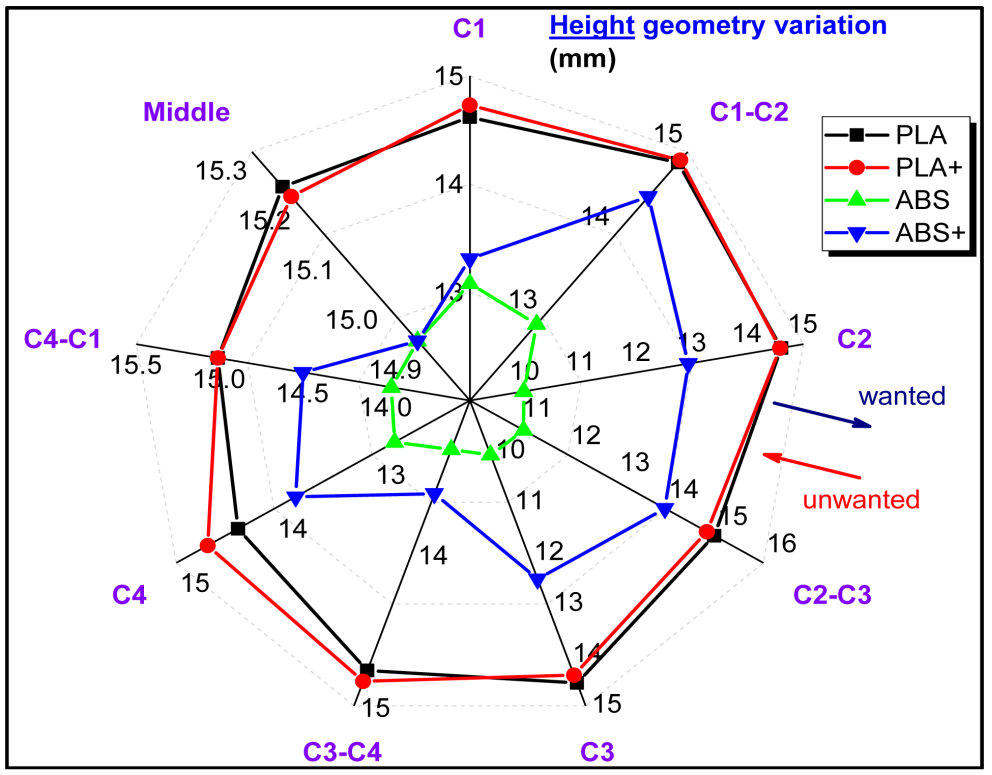

(a)

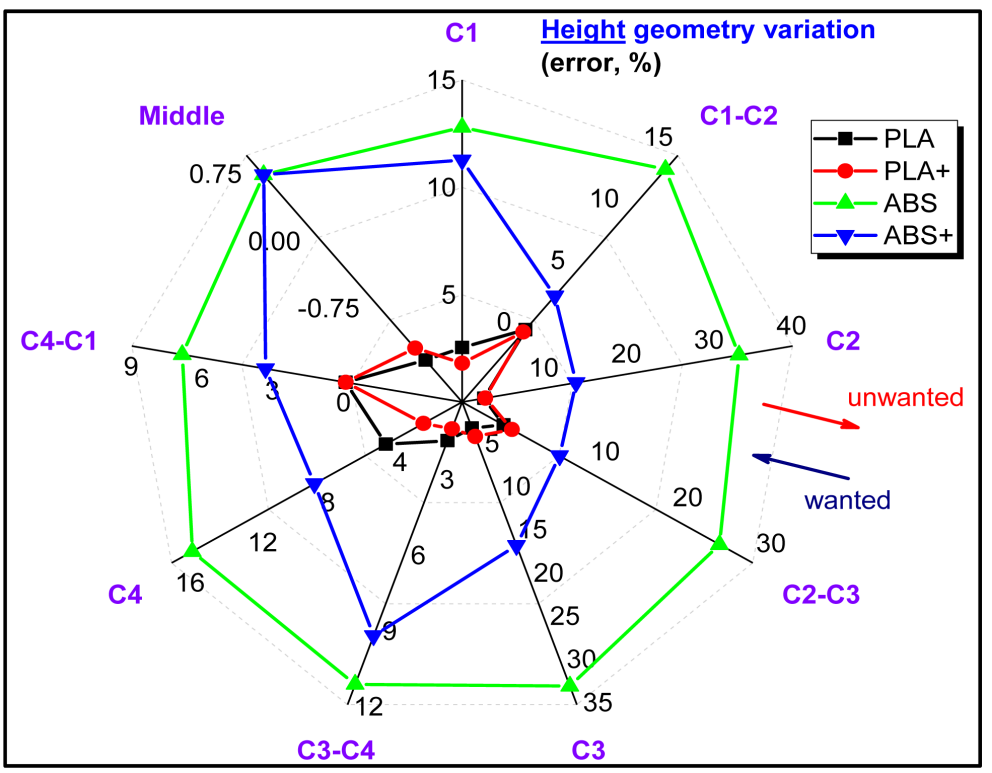

(b)

Figure 8. Height geometry variation represented as (a) mm variation and (b) error variation.

with $16.60 \%$ shape error to $14.92 \mathrm{~mm}$ with $0.53 \%$ shape error, respectively. Indeed, with ABS engineering thermoplastic material, deviation from the true value $(15 \mathrm{~mm})$ reached the maximum shape error by almost $33.53 \%$ which is equal to $9.97 \mathrm{~mm}$. This is the fact that the solidification process which is more likely to be related to nozzle temperature needs more time to heal and also needs high nozzle temperature to stabilize and cool down slowly. It is also noticeable that the shape error variation on each corner and each face for specimens fabricated with the open-source system using PLA and PLA+ thermoplastic materials have not exceeded $3.00 \%$ indicating that less warping deformation and dimensional 
variation might occur, whereas $\mathrm{ABS}$ and $\mathrm{ABS}+$ thermoplastic materials reached almost $34.53 \%$ indicating that high warping deformation and dimensional variation might occur in these filament materials as the volumetric shrinkage is quite visible.

Figure 9 shows the normal Q-Q plot for PLA, PLA+, ABS and ABS+. The blue circles in this $\mathrm{Q}-\mathrm{Q}$ plot start out on one side of the line, then are almost entirely on the other side for a long stretch, then move to the other side of the reference line again. This behavior indicates some degree of skewing. It can be assumed that the data measured for the surface roughness was left-skewed data distributed as the points were roughly started consistently above the reference line (45-degree reference line), then stay some point below the reference line and then rise again above the reference line. In Figure 9(a), the mean and standard deviation of the normal Q-Q distribution plot of PLA for the height geometry

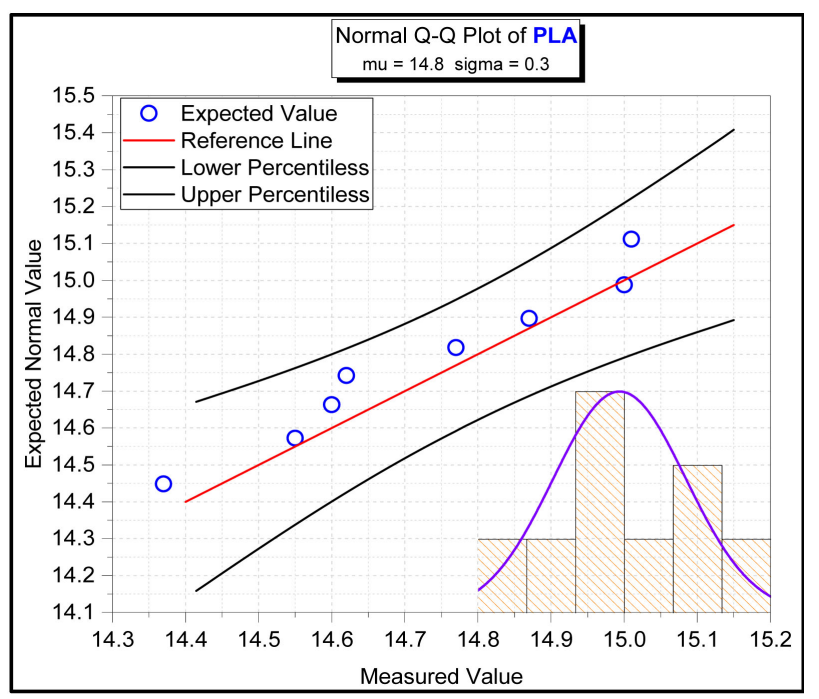

(a)

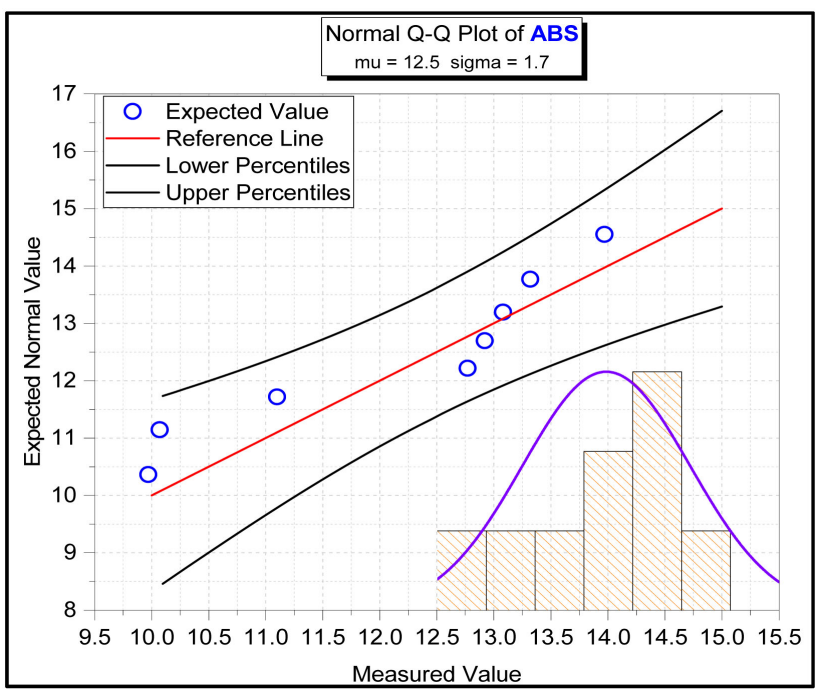

(c)

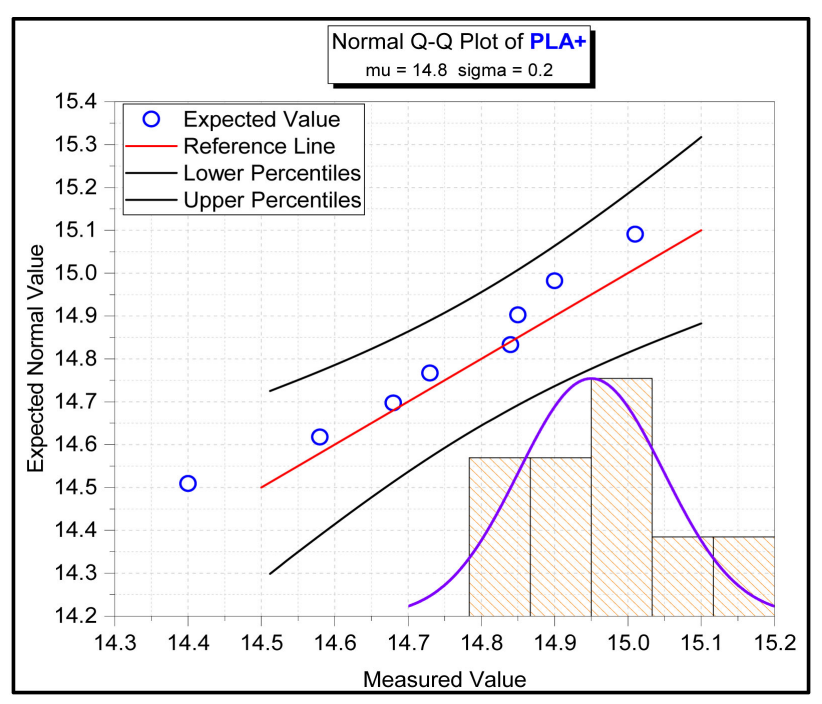

(b)

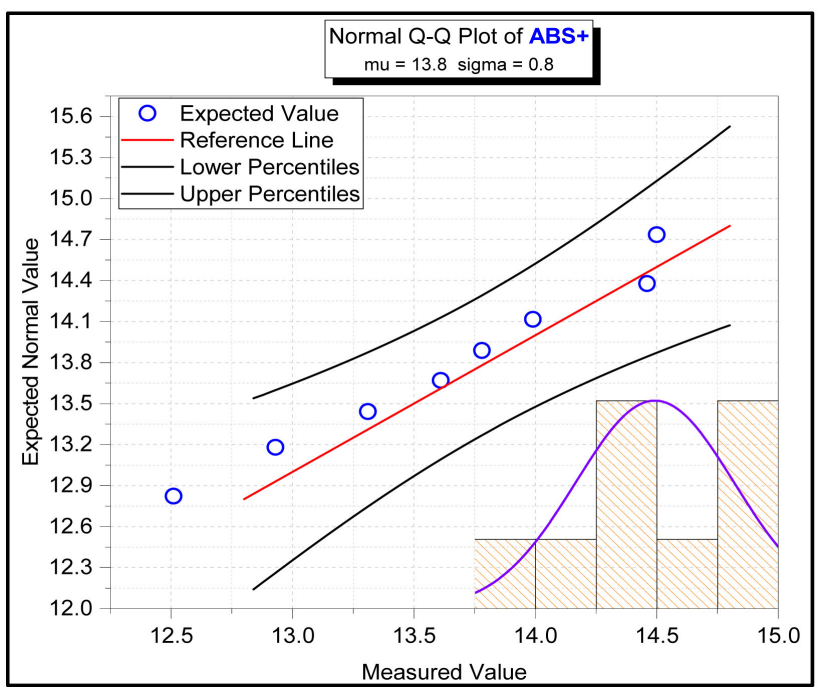

(d)

Figure 9. Normal Q-Q plot of (a) PLA; (b) PLA+; (c) ABS and (d) ABS+. 
variation was $14.8 \pm 0.3 \mathrm{~mm}$. While, in Figure $9(\mathrm{~b})$, the mean and standard deviation of the normal Q-Q distribution plot of PLA+ for the height geometry variation was $14.8 \pm 0.2 \mathrm{~mm}$, indicating the same height geometry variation was observed with only small variation of $\pm 0.3 \mathrm{~mm}$ and $\pm 0.2 \mathrm{~mm}$ for PLA and PLA+, respectively. However, in Figure $9(\mathrm{c})$, the mean and standard deviation of the normal Q-Q distribution plot of ABS for the height geometry variation was 12.5 $\pm 1.7 \mathrm{~mm}$, whereas, in Figure 9 (d), the mean and standard deviation of the normal Q-Q distribution plot of ABS+ for the height geometry variation was $13.8 \pm 0.8 \mathrm{~mm}$, indicating that there is unwanted variation in the height geometry that was observed with a big variation of $\pm 1.7 \mathrm{~mm}$ and $\pm 0.8 \mathrm{~mm}$ for ABS and $\mathrm{ABS}+$, respectively.

\subsection{Surface Profile Assessments}

Figure 10 showed the measured surface profile values for each position of the

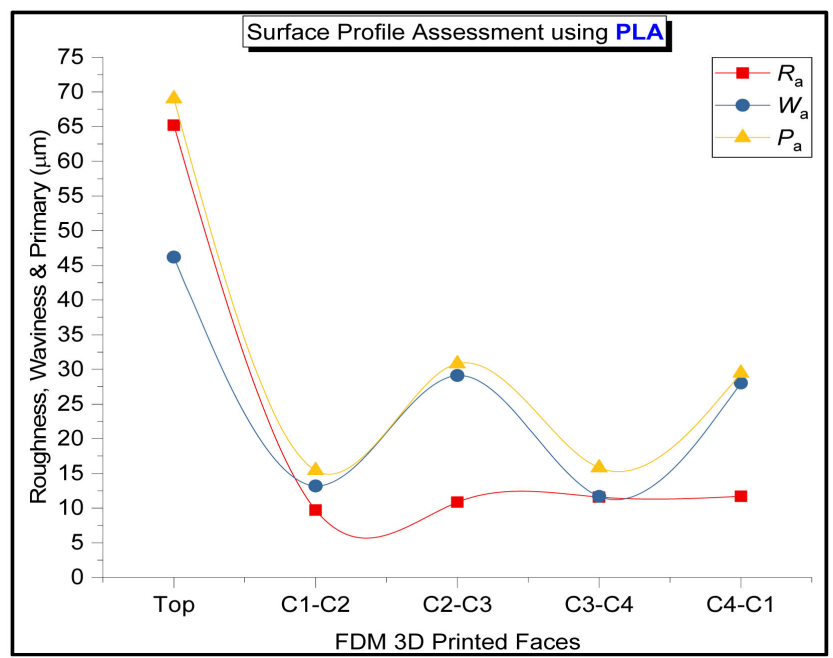

(a)

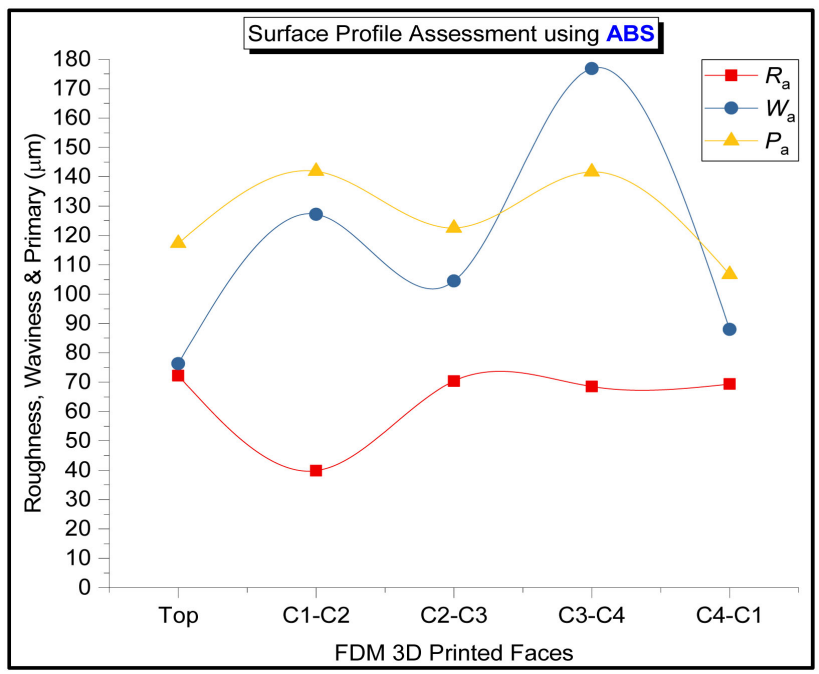

(c)

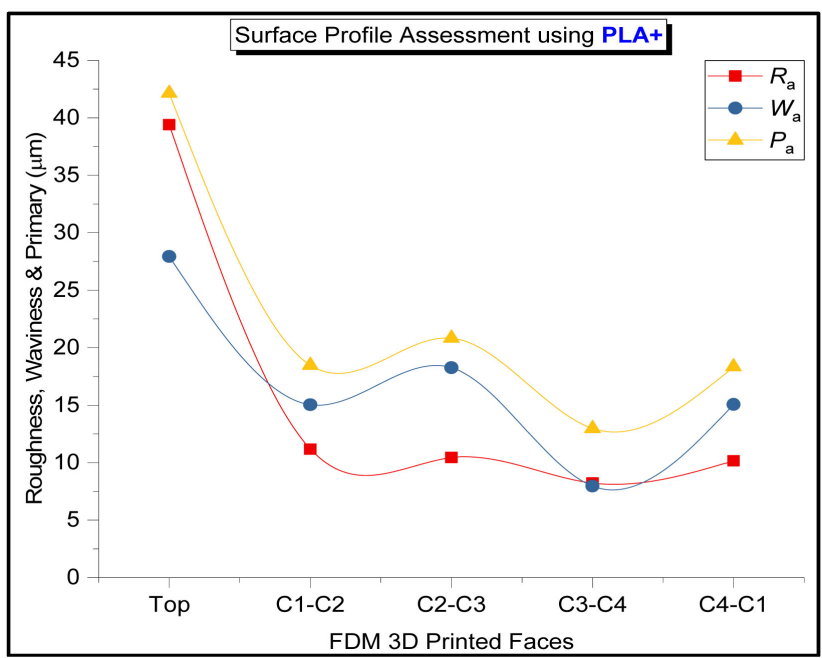

(b)

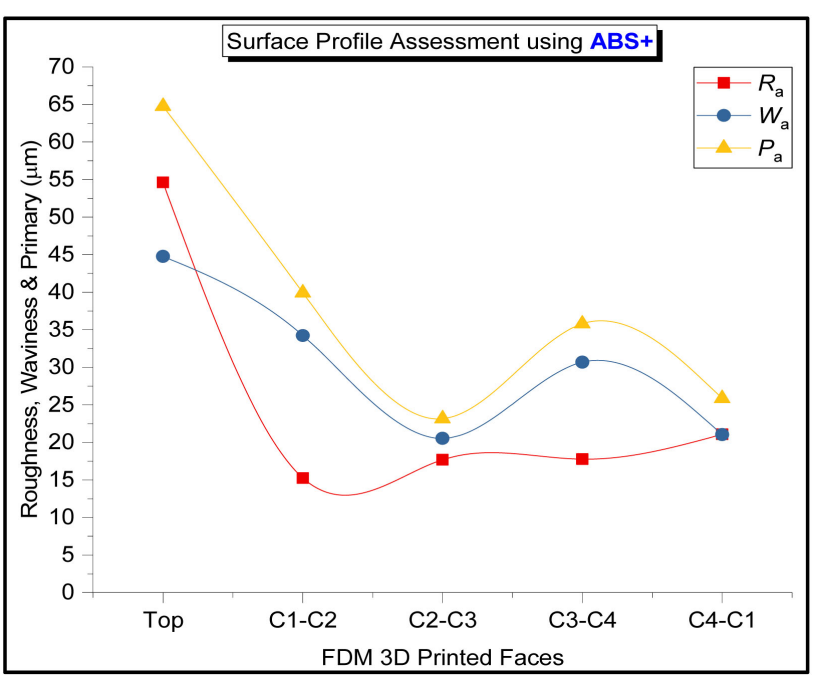

(d)

Figure 10. Surface profile assessment of (a) PLA; (b) PLA+; (c) ABS and (d) ABS+. 
FDM 3D printed faces (top, C1-C2, C2-C3, C3-C4, C4-C1) and considered surface roughness, $R_{\mathrm{a}}$, waviness, $W_{\mathrm{a}}$, and primary, $P_{\mathrm{a}}$, values were calculated by considering $90^{\circ}$ measuring direction (perpendicular to building direction). According to the experimentally obtained data, variations were observed in the surface profile distribution curves caused by different engineering thermoplastic filament materials. Several irregular steps and micro-sized burrs were observed. Consequently, the actual surface profile distribution was influenced by several factors and conditions such as the build style and material property. Each surface profile distribution of PLA, PLA+, ABS and ABS+ has its characteristics.

In general, PLA, PLA+, ABS and ABS+ follows the same patterns at the top faces which represents the highest surface roughness, $R_{\mathrm{a}}$, compared to other four identical faces despite the low nozzle diameter which indicates a minor influence of the nozzle diameter on the surface roughness. The obtained values were roughly $\sim 65.19 \mu \mathrm{m}$ (for PLA), $39.39 \mu \mathrm{m}$ (for PLA+), $72.22 \mu \mathrm{m}$ (for ABS) and $\sim 54.62 \mu \mathrm{m}$ (for ABS+). Roughly speaking, PLA, PLA+ and ABS+ shows the same surface roughness, waviness and primary behaviour where the top faces reach the high value of $R_{\mathrm{a}}, W_{\mathrm{a}}$ and $P_{\mathrm{a}}$ and then drop dramatically by almost $80 \%$ at other faces, whereas ABS shows irregularity distribution in the surface roughness, waviness and primary for all faces including the top face (middle) and there is no distinctive pattern to observe.

Figure 11 illustrates the mean and standard deviation (mean \pm SD) of the measured surface profile values for each FDM 3D printed part with and without the top face by considering $90^{\circ}$ measuring direction (perpendicular to building direction).

For PLA engineering plastic as shown in Figure 11(a), the mean \pm SD values with a top face for $R_{\mathrm{a}}, W_{\mathrm{a}}$ and $P_{\mathrm{a}}$ were $21.8 \pm 21.7 \mu \mathrm{m}, 25.6 \pm 12.6 \mu \mathrm{m}$ and $32.1 \pm$ $19.6 \mu \mathrm{m}$, respectively. Whereas the mean \pm SD values without a top face for $R_{\mathrm{a}}$, $W_{\mathrm{a}}$ and $P_{\mathrm{a}}$ were $11 \pm 0.8 \mu \mathrm{m}, 20.5 \pm 8.1 \mu \mathrm{m}$ and $22.9 \pm 7.3 \mu \mathrm{m}$, respectively.

For PLA+ engineering plastic as shown in Figure 11(b), the mean \pm SD values with a top face for $R_{\mathrm{a}}, W_{\mathrm{a}}$ and $P_{\mathrm{a}}$ were $15.9 \pm 11.8 \mu \mathrm{m}, 16.9 \pm 6.5 \mu \mathrm{m}$ and $22.5 \pm$ $10.1 \mu \mathrm{m}$, respectively. Whereas the mean $\pm \mathrm{SD}$ values without a top face for $R_{\mathrm{a}}$, $W_{\mathrm{a}}$ and $P_{\mathrm{a}}$ were $10 \pm 1.1 \mu \mathrm{m}, 14.1 \pm 3.8 \mu \mathrm{m}$ and $17.7 \pm 2.9 \mu \mathrm{m}$, respectively.

For ABS engineering plastic as shown in Figure 11(c), the mean \pm SD values with a top face for $R_{\mathrm{a}}, W_{\mathrm{a}}$ and $P_{\mathrm{a}}$ were $64.1 \pm 12.2 \mu \mathrm{m}, 114.6 \pm 35.5 \mu \mathrm{m}$ and $126 \pm$ $13.8 \mu \mathrm{m}$, respectively. Whereas the mean $\pm \mathrm{SD}$ values without a top face for $R_{\mathrm{a}}$, $W_{\mathrm{a}}$ and $P_{\mathrm{a}}$ were $62 \pm 12.8 \mu \mathrm{m}, 124.1 \pm 33.5 \mu \mathrm{m}$ and $128.2 \pm 14.7 \mu \mathrm{m}$, respectively.

For ABS+ engineering plastic, as shown in Figure 11(d), the mean \pm SD values with a top face for $R_{\mathrm{a}}, W_{\mathrm{a}}$ and $P_{\mathrm{a}}$ were $25.3 \pm 14.8 \mu \mathrm{m}, 30.2 \pm 9 \mu \mathrm{m}$ and $37.9 \pm$ $14.8 \mu \mathrm{m}$, respectively. Whereas the mean $\pm \mathrm{SD}$ values without a top face for $R_{\mathrm{a}}$, $W_{\mathrm{a}}$ and $P_{\mathrm{a}}$ were $17.9 \pm 2.1 \mu \mathrm{m}, 26.6 \pm 6 \mu \mathrm{m}$ and $31.2 \pm 6.9 \mu \mathrm{m}$, respectively.

Generally, the drop in the mean and standard deviation values when excluding the top face indicates that the measuring direction plays a substantial role in determining the surface roughness, waviness and primary behaviour of all printed parts. Besides, there is a low interaction between raster angle $\left( \pm 45^{\circ}\right)$ and 


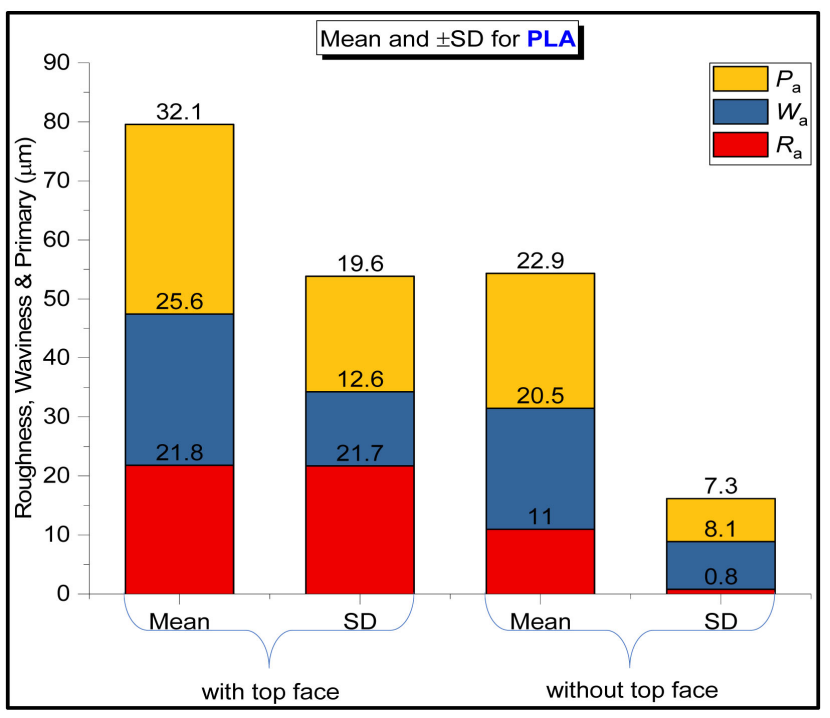

(a)

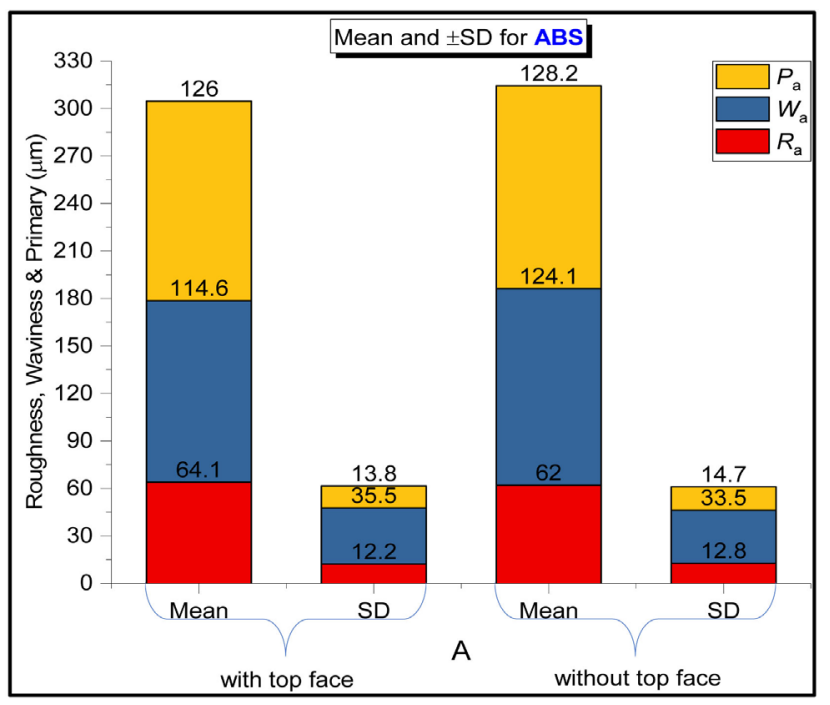

(c)

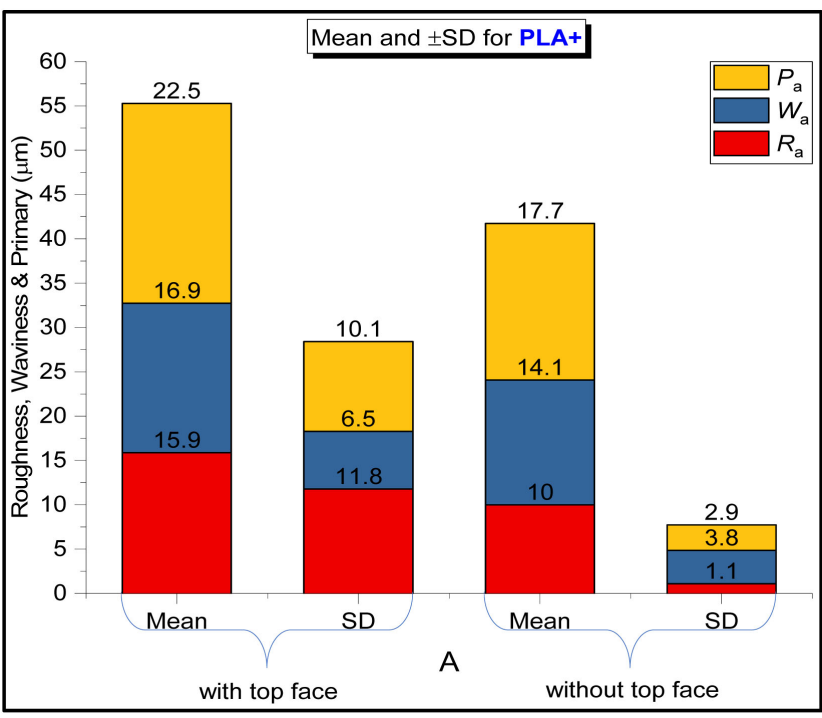

(b)

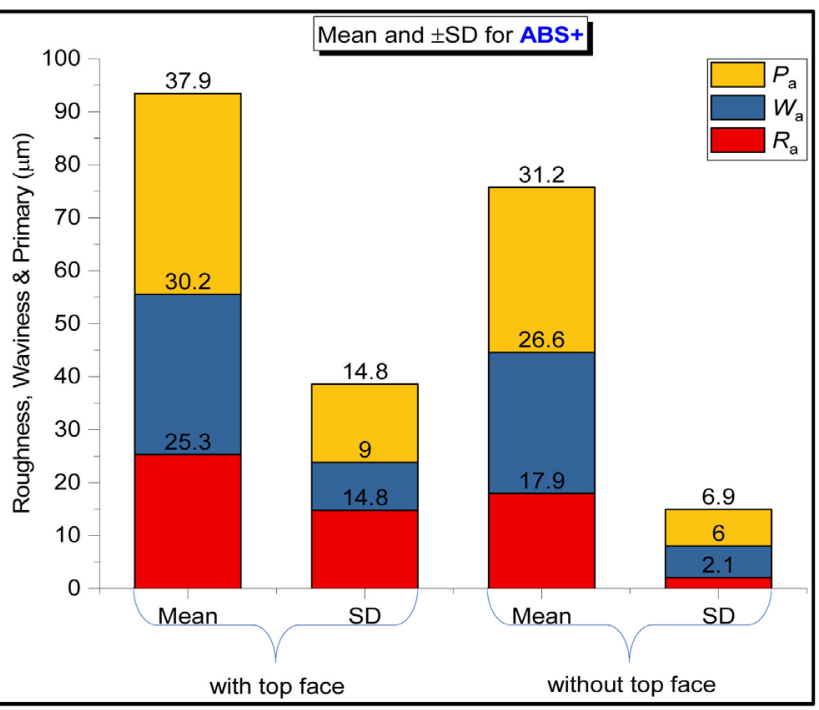

(d)

Figure 11. Mean and standard deviation of the surface profile assessment of (a) PLA; (b) PLA+; (c) ABS and (d) ABS+.

slice height for the top face (middle), whereas for the four-identical side faces this interaction in the only significant one. Based on this finding for all FDM 3D printed parts, the performance of the surface roughness, waviness and primary in the range from an excellent performance to worth performance were as flows $\mathrm{PLA}+<\mathrm{PLA}<\mathrm{ABS}<\mathrm{ABS}+$.

Figure 12 shows the two-dimensional (2D) surface profile ratio of the $R_{\mathrm{q}} / R_{\mathrm{a}}$, $W_{\mathrm{q}} / W_{\mathrm{a}}$ and $P_{\mathrm{q}} / P_{\mathrm{a}}$ for all printed parts. For PLA thermoplastic filament material, the ratio of the average root means square $\left(R_{\mathrm{q}}, W_{\mathrm{q}}\right.$ and $\left.P_{\mathrm{q}}\right)$ to average surface roughness, waviness and primary $\left(R_{\mathrm{a}}, W_{\mathrm{a}}\right.$ and $\left.P_{\mathrm{a}}\right)$ for $R_{\mathrm{q}} / R_{\mathrm{a}}, W_{\mathrm{q}} / W_{\mathrm{a}}$ and $P_{\mathrm{q}} / P_{\mathrm{a}}$ was found to be randomly varying with constant deviation of around $1.25 \pm$ $0.03,1.22 \pm 0.03$ and $1.24 \pm 0.03$, respectively, which is very small and is tolerable. For PLA+ thermoplastic filament material, the ratio of the average root 


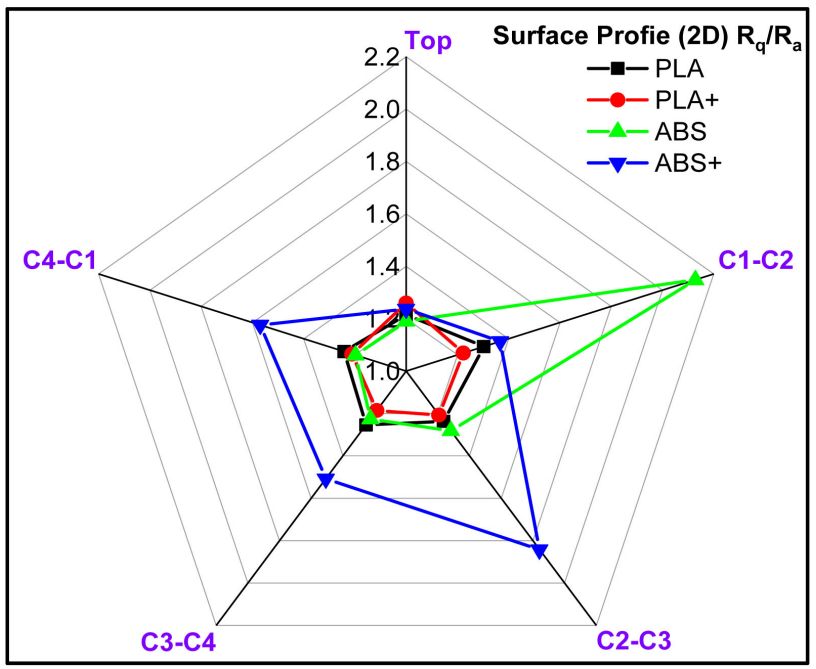

(a)

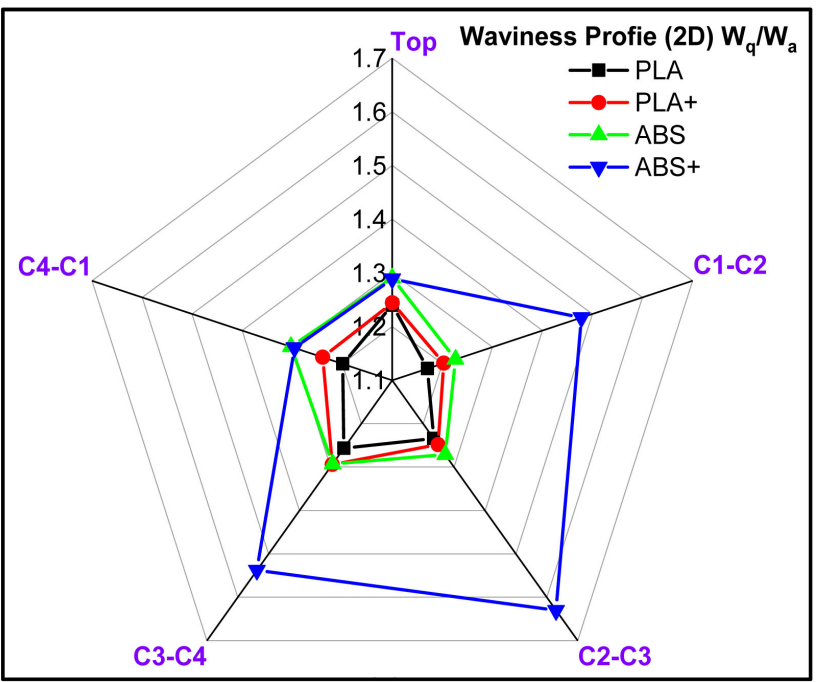

(b)

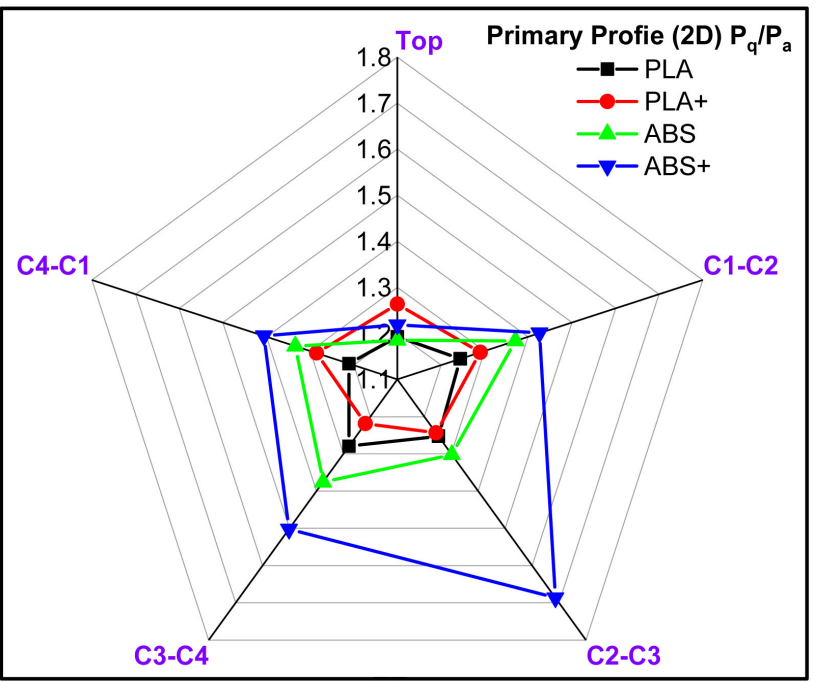

(c)

Figure 12. Surface profile (2D) of (a) $R_{\mathrm{q}} / R_{\mathrm{a}}$; (b) $W_{\mathrm{q}} / W_{\mathrm{a}}$ and (c) $P_{\mathrm{q}} / P_{\mathrm{a}}$. 
means square $\left(R_{\mathrm{q}}, W_{\mathrm{q}}\right.$ and $\left.P_{\mathrm{q}}\right)$ to average surface roughness, waviness and primary $\left(R_{\mathrm{a}}, W_{\mathrm{a}}\right.$ and $\left.P_{\mathrm{a}}\right)$ for $R_{\mathrm{q}} / R_{\mathrm{a}}, W_{\mathrm{q}} / W_{\mathrm{a}}$ and $P_{\mathrm{q}} / P_{\mathrm{a}}$ was found to be randomly varying with almost constant deviation of around $1.22 \pm 0.02,1.25 \pm 0.03$ and 1.26 \pm 0.03 , respectively. For ABS thermoplastic filament material, the ratio of the average root means square $\left(R_{\mathrm{q}}, W_{\mathrm{q}}\right.$ and $\left.P_{\mathrm{q}}\right)$ to average surface roughness, waviness and primary $\left(R_{\mathrm{a}}, W_{\mathrm{a}}\right.$ and $\left.P_{\mathrm{a}}\right)$ for $R_{\mathrm{q}} / R_{\mathrm{a}}, W_{\mathrm{q}} / W_{\mathrm{a}}$ and $P_{\mathrm{q}} / P_{\mathrm{a}}$ was found to be randomly varying in both mean and standard deviation of around $1.40 \pm 0.36$, $1.28 \pm 0.03$ and $1.31 \pm 0.07$, respectively. For ABS+ thermoplastic filament material, the ratio of the average root means square $\left(R_{\mathrm{q}}, W_{\mathrm{q}}\right.$ and $\left.P_{\mathrm{q}}\right)$ to average surface roughness, waviness and primary $\left(R_{\mathrm{a}}, W_{\mathrm{a}}\right.$ and $\left.P_{\mathrm{a}}\right)$ for $R_{\mathrm{q}} / R_{\mathrm{a}}, W_{\mathrm{q}} / W_{\mathrm{a}}$ and $P_{\mathrm{q}} / P_{\mathrm{a}}$ was found to be randomly varying with almost constant deviation of around $1.50 \pm 0.20,1.45 \pm 0.13$ and $1.45 \pm 0.15$, respectively.

Noticeably, PLA and PLA+ show an excellent surface profile ratio with almost constant deviation in surface roughness, waviness and primary. Whereas ABS and $\mathrm{ABS}+$ show unacceptable surface profile ratio with random variation in deviation in surface roughness, waviness and primary. Ideally, $R_{\mathrm{q}} / R_{\mathrm{a}}, W_{\mathrm{q}} / W_{\mathrm{a}}$ and $P_{\mathrm{q}} / P_{\mathrm{a}}$ are equal to 1.22 (for $2 \mathrm{D}$ ) with minimum deviation is an excellent surface profile ratio, as the $R_{\mathrm{q}}$ is very sensitive to peaks and valleys than $R_{\mathrm{a}}$ because of the fact that the amplitudes are squared.

Figure 13 shows the skewness $\left(R_{\mathrm{sk}}, W_{\mathrm{sk}}\right.$ and $\left.P_{\mathrm{sk}}\right) 3^{\text {rd }}$ moment versus the kurtosis $\left(R_{\mathrm{ku}}, W_{\mathrm{ku}}\right.$ and $\left.P_{\mathrm{ku}}\right) 4^{\text {th }}$ moment of all FDM 3D printed parts. Ideally, a value of zero for skewness and three for kurtosis is typical for a random, Gaussian profile and weakly isotropic.

In Figure 13(a), the general trend of PLA thermoplastic filament material showed positive skewness ( $+v e$ for steep peaks and flat valleys) and negative skewness (-ve for flat peaks and steep valleys) but not equally distributed between them which is more likely to be negative skewed by almost $95 \%$ than positive skewed by almost $5 \%$ for surface roughness, waviness and primary. The maximum and minimum trend of skewness and kurtosis was in the range of $-1.2 \leq R_{\mathrm{sk}} \leq 0.13$ and $2.76 \leq R_{\mathrm{ku}} \leq 4.03$ (for surface roughness), $-0.99 \leq W_{\mathrm{sk}} \leq$ 0.34 and $2.42 \leq W_{\mathrm{ku}} \leq 3.35$ (for waviness) and $-1.16 \leq P_{\mathrm{sk}} \leq 0.29$ and $2.54 \leq P_{\mathrm{ku}} \leq$ 4.71 (for primary). Based on skewness and kurtosis results obtained from printed parts on all faces, the PLA showed both leptokurtic and platykurtic distribution with high and low degree of peakedness as $R_{\mathrm{ku}}, W_{\mathrm{ku}}$ and $P_{\mathrm{ku}}$ represent both less and greater than 3 .

In Figure 13(b), the general trend of PLA+ thermoplastic filament material showed a $100 \%$ negative skewness ( - ve for flat peaks and steep valleys) for surface roughness waviness and primary indicate more resistance to abrasive erosion. The maximum and minimum trend of skewness and kurtosis was in the range of $-1.46 \leq R_{\mathrm{sk}} \leq-0.02$ and $2.14 \leq R_{\mathrm{ku}} \leq 4.1$ (for surface roughness), -1.06 $\leq W_{\mathrm{sk}} \leq-0.03$ and $2.7 \leq W_{\mathrm{ku}} \leq 3.15$ (for waviness) and $-1.49 \leq P_{\mathrm{sk}} \leq-0.23$ and $2.7 \leq P_{\mathrm{ku}} \leq 5.77$ (for primary). Based on skewness and kurtosis results obtained from printed parts on all faces, the PLA+ showed both leptokurtic and platykurtic 


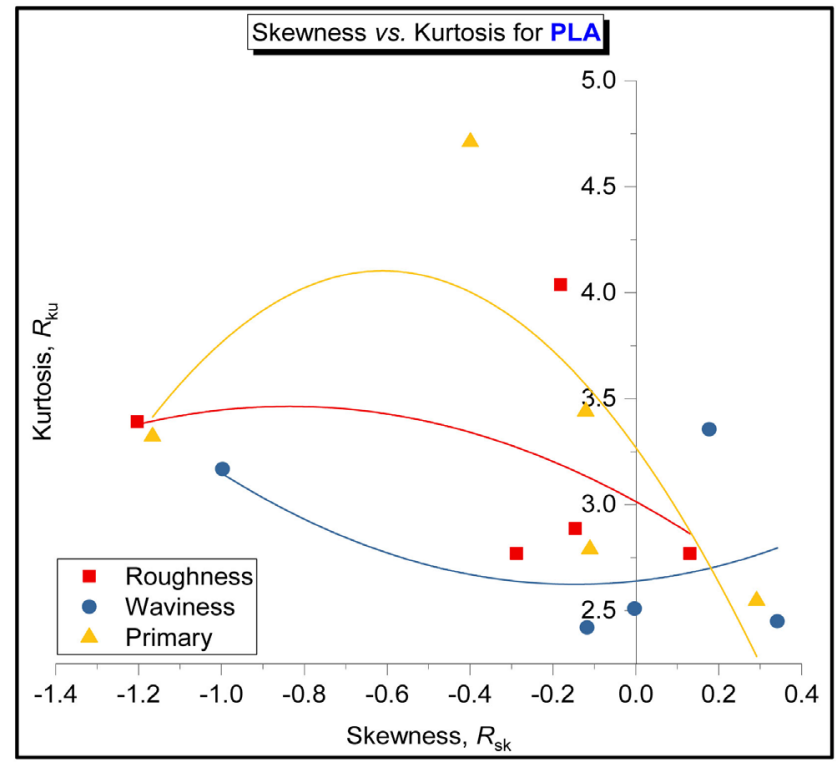

(a)

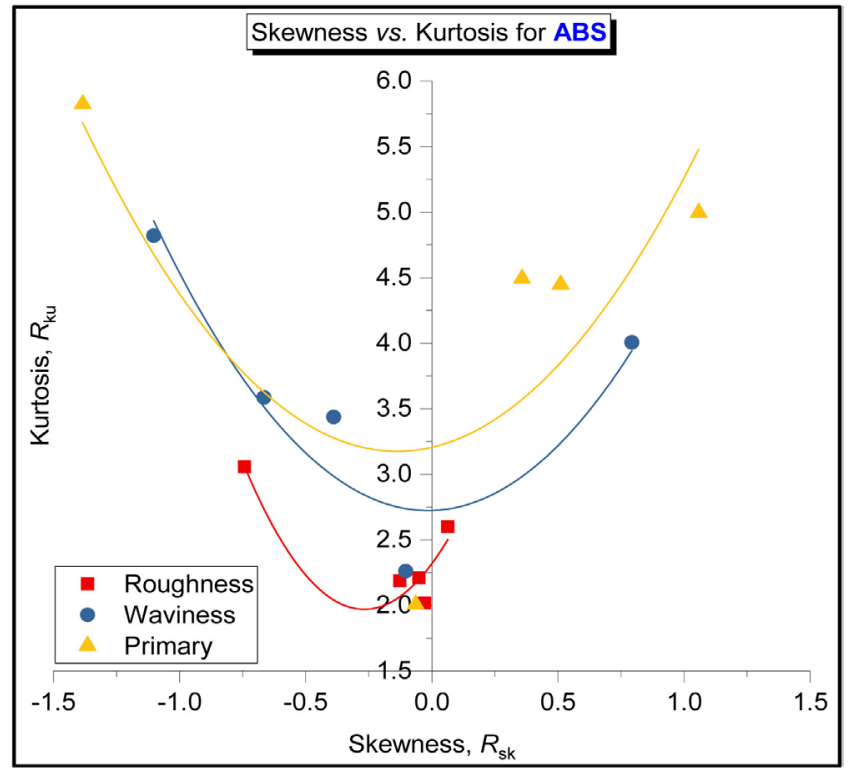

(c)

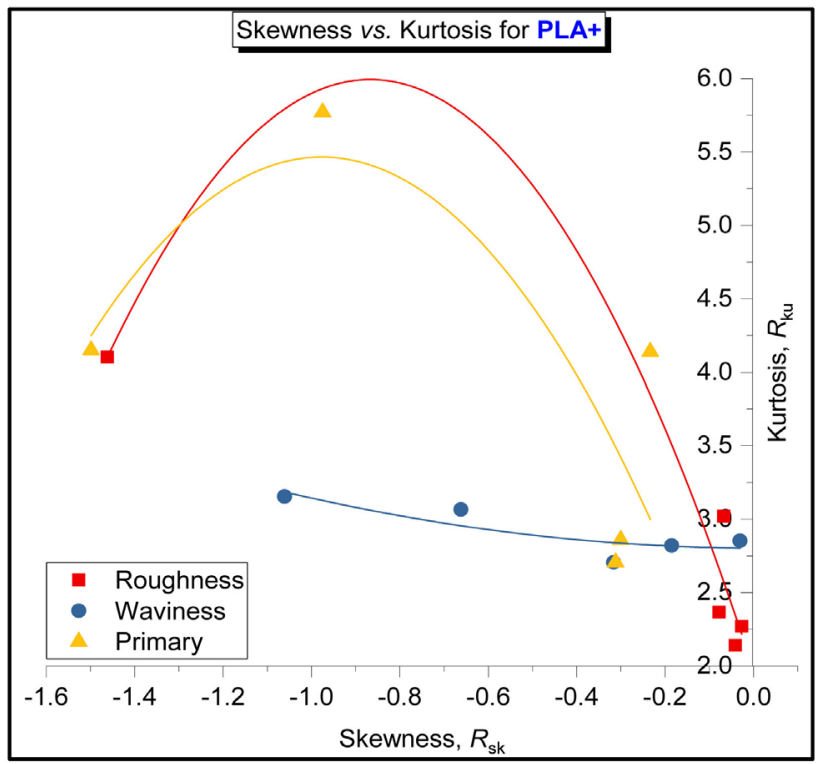

(b)

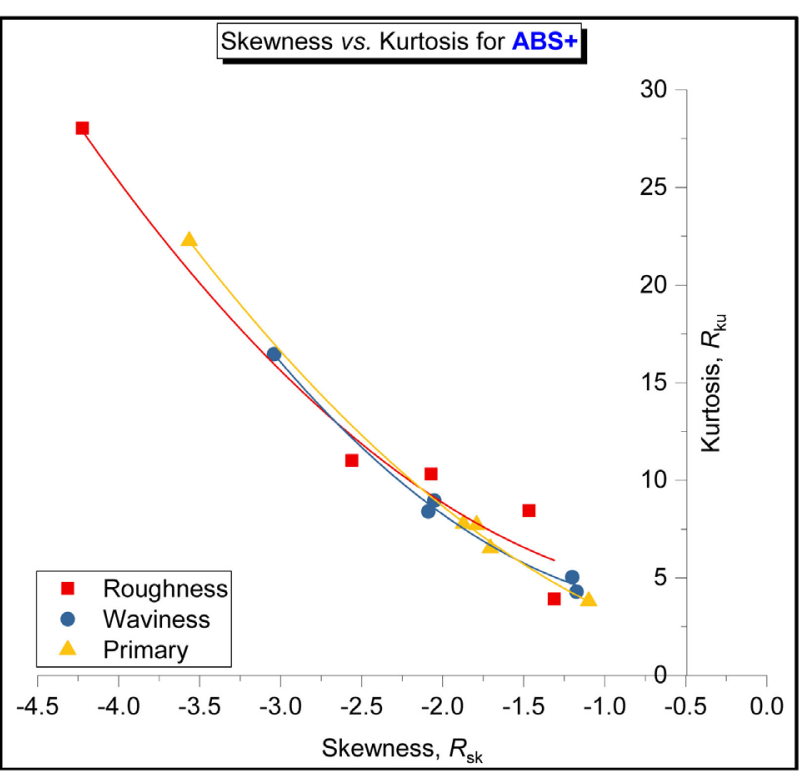

(d)

Figure 13. Skewness vs. kurtosis of (a) PLA; (b) PLA+; (c) ABS and (d) ABS+.

distribution with high and low degree of peakedness as $R_{\mathrm{ku}}, W_{\mathrm{ku}}$ and $P_{\mathrm{ku}}$ represent both less and greater than 3 .

In Figure 13(c), the general trend of ABS thermoplastic filament material showed $5 \%$ positive skewness (+ ve for steep peaks and flat valleys) and $95 \%$ negative skewness ( $-v e$ for flat peaks and steep valleys) for the surface roughness and almost equally distributed over waviness and primary. The maximum and minimum trend of skewness and kurtosis was in the range of $-0.74 \leq R_{\mathrm{sk}} \leq-0.02$ and $2.01 \leq R_{\mathrm{ku}} \leq 3.05$ (for surface roughness), $-1.1 \leq W_{\mathrm{sk}} \leq 0.79$ and $2.26 \leq W_{\mathrm{ku}}$ $\leq 4.01$ (for waviness) and $-1.39 \leq P_{\mathrm{sk}} \leq 1.05$ and $2.01 \leq P_{\mathrm{ku}} \leq 5.82$ (for primary). Based on skewness and kurtosis results obtained from printed parts on all faces, 
the ABS showed both leptokurtic and platykurtic distribution with high and low degree of peakedness as $R_{\mathrm{ku}}, W_{\mathrm{ku}}$ and $P_{\mathrm{ku}}$ represent both less and greater than 3 .

In Figure 13(d), the general trend of ABS+ thermoplastic filament material showed only negative skewness ( $-v e$ for flat peaks and steep valleys) for surface roughness, waviness and primary. The maximum and minimum trend of skewness and kurtosis was in the range of $-4.22 \leq R_{\mathrm{sk}} \leq-1.31$ and $3.92 \leq R_{\mathrm{ku}} \leq 28.04$ (for surface roughness), $-3.04 \leq W_{\mathrm{sk}} \leq-1.17$ and $4.28 \leq W_{\mathrm{ku}} \leq 16.45$ (for waviness) and $-1.09 \leq P_{\mathrm{sk}} \leq 3.56$ and $3.81 \leq P_{\mathrm{ku}} \leq 22.25$ (for primary). It is noticed that the ABS+ showed a leptokurtic distribution with high degree of peakedness only as $R_{\mathrm{ku}}, W_{\mathrm{ku}}$ and $P_{\mathrm{ku}}>3$.

The values of skewness $\left(R_{\mathrm{sk}}, W_{\mathrm{sk}}\right.$ and $\left.P_{\mathrm{sk}}\right) 3^{\text {rd }}$ moment and the kurtosis $\left(R_{\mathrm{ku}}\right.$, $W_{\mathrm{ku}}$ and $\left.P_{\mathrm{ku}}\right)$ are strongly influenced by different thermoplastic filament materials. Most of the surface texture of the printed parts by PLA, PLA+ and ABS is characterized by small values of $\left(R_{\mathrm{sk}}, W_{\mathrm{sk}}\right.$ and $\left.P_{\mathrm{sk}}\right)$ and $\left(R_{\mathrm{ku}}, W_{\mathrm{ku}}\right.$ and $\left.P_{\mathrm{ku}}\right)$, on the other hand, ABS is characterized by large values of $\left(R_{\mathrm{sk}}, W_{\mathrm{sk}}\right.$ and $\left.P_{\mathrm{sk}}\right)$ and $\left(R_{\mathrm{ku}}\right.$, $W_{\mathrm{ku}}$ and $\left.P_{\mathrm{ku}}\right)$. PLA+ and ABS+ plots display a negative skewness distribution, $\left(R_{\mathrm{sk}}, W_{\mathrm{sk}}\right.$ and $\left.P_{\mathrm{sk}}<0\right)$, close to zero in magnitude, which will be valuable for a great many applications, whereas values of $\left(R_{\mathrm{sk}}, W_{\mathrm{sk}}\right.$ and $\left.P_{\mathrm{sk}}<0\right)$ mean deeper-larger amplitude profile valleys in the whole printed parts of almost all examined target thermoplastic filament materials.

\subsection{Surface Profile Height Assessment}

The $R_{\mathrm{k}}$ group parameter (core roughness depth, $R_{\mathrm{k}}$, reduced peak height, $R_{\mathrm{pk}}$, reduced valley depth, $R_{\mathrm{vk}}$, material portion $1, \mathrm{M}_{\mathrm{r} 1}$, and material portion $2, \mathrm{M}_{\mathrm{r} 2}$ ) is derived from the bearing ratio curve based on the ISO 13565-2:1996 standard (Abbott curve, which represents mathematically the cumulative probability density function of the profile height of a surface and can be calculated by integrating the profile trace). Bear in minds that $R_{\mathrm{pk}}$ (in $\mu \mathrm{m}$ ) and $\mathrm{M}_{\mathrm{r} 1}$ (in \%) represents the peaks of the FDM 3D printed parts of all thermoplastic filament materials. Whereas $R_{\mathrm{vk}}$ (in $\mu \mathrm{m}$ ) and $\mathrm{M}_{\mathrm{r} 2}$ (in \%) represents the valleys of the FDM 3D printed parts of all thermoplastic filament materials, and $R_{\mathrm{k}}$ (in $\mu \mathrm{m}$ ) represents the core/kernel of printed parts. These parameters were precisely designed for the control of the potential wear in cylinder bores in the automotive industry. They attempt to find and describe in numeric terms the wear characteristics of the bore by use of a material ratio curve.

Here, $R_{\mathrm{k}}$ (core), $R_{\mathrm{pk}}$ (peaks) and $R_{\mathrm{vk}}$ (valleys) were examined for all FDM 3D printed parts by considering different thermoplastic filament materials namely PLA, PLA+, ABS and BAS+. The bearing area curve tells us how much of the surface behaviour is above a certain height. More significant bearing area sample after FDM 3D technology is equivalent to most of the surface is close to the peak of the surface. The $R_{\mathrm{pk}}$ (peaks) and $R_{\mathrm{vk}}$ (valleys) parameters can have an influence on friction. Large $R_{\mathrm{k}}$ parameter in FDM surface value implies a surface composed of high peaks providing small initial contact area (point or line) and thus high contact stress areas when the surface is contacted. 
Figure 14 shows the differences in roughness profiles of all FDM 3D printed samples for the material ratio assessment $\left(R_{\mathrm{k}}, R_{\mathrm{pk}}\right.$ and $\left.R_{\mathrm{vk}}\right)$. Higher roughness parameters in FDM 3D sample lead to a decrease of friction providing a small initial contact area. The distribution of ABS printed sample is characterized by a significant fluctuation of changes in the value of $R_{\mathrm{k}}$ (core), $R_{\mathrm{pk}}$ (peaks) and $R_{\mathrm{vk}}$ (valleys) parameters. This proves that the surface profile of the ABS printed sample has undirected structure. Also, it can be seen that the $R_{\mathrm{vk}}$ (valleys) parameter for PLA, PLA+ and ABS+ at the top face exhibit very high values of almost $184.14 \mu \mathrm{m}, 128.68 \mu \mathrm{m}$ and $198.17 \mu \mathrm{m}$, respectively. Whereas, the $R_{\mathrm{vk}}$ (valleys) parameter for ABS at the top face exhibits slightly less value than other filaments by just about $116.8 \mu \mathrm{m}$.

Generally, based on the data obtained from Figure 14, the mean and standard deviation (mean $\pm \mathrm{SD}$ ) of $R_{\mathrm{k}}$ (core), $R_{\mathrm{pk}}$ (peaks) and $R_{\mathrm{vk}}$ (valleys) for PLA including the top face was $33.97 \pm 4.43 \mu \mathrm{m}, 5.50 \pm 1.13 \mu \mathrm{m}$ and $45.17 \pm 69.50 \mu \mathrm{m}$.

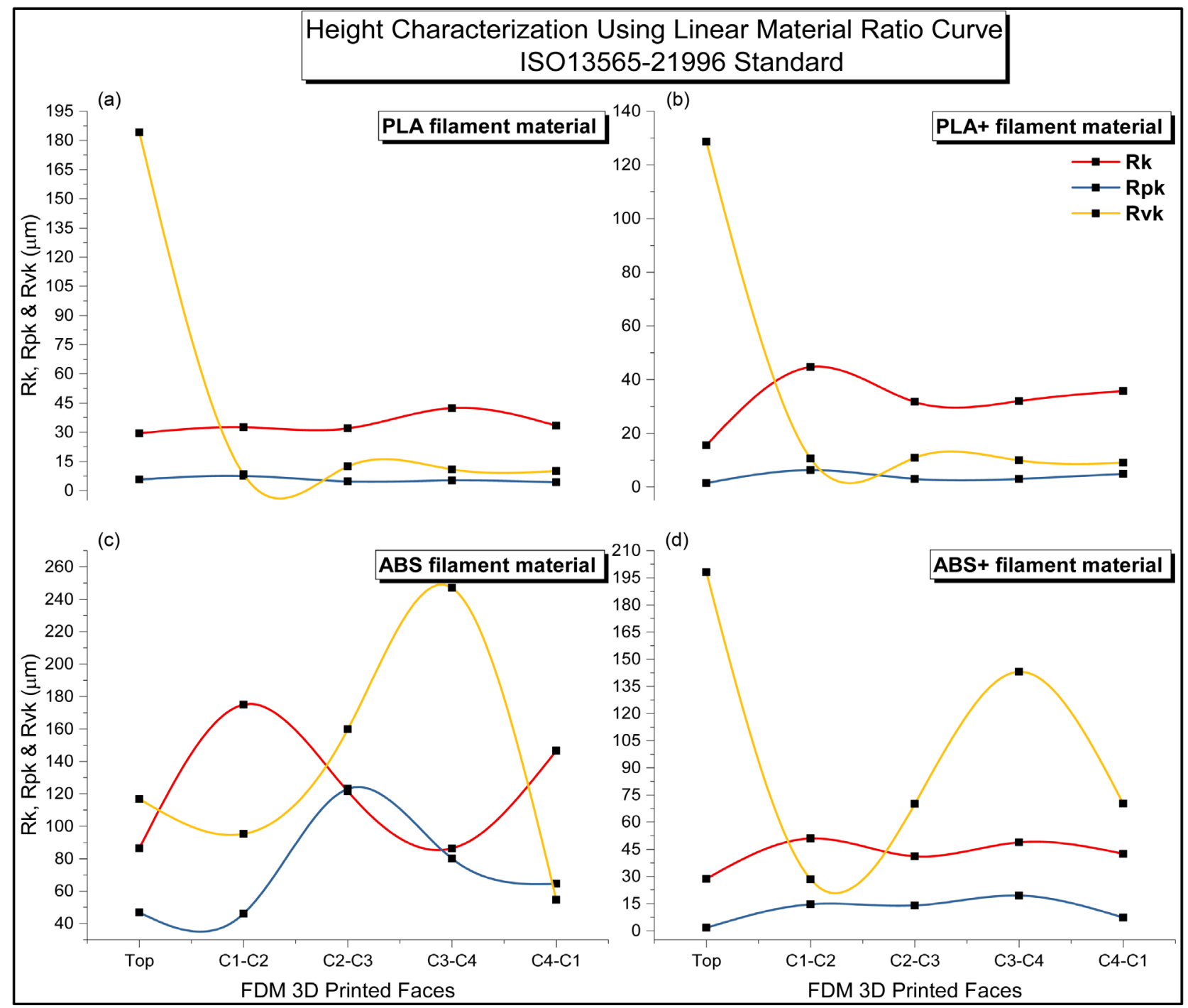

Figure 14. Material ratio assessment $\left(R_{\mathrm{k}}, R_{\mathrm{pk}} \& R_{\mathrm{vk}}\right)$ of (a) PLA; (b) PLA+; (c) ABS and (d) ABS+. 
When excluding the top face, the $R_{\mathrm{k}}$ (core) increased by almost $3 \%, R_{\mathrm{pk}}$ (peaks) remains almost the same and $R_{\mathrm{vk}}$ (valleys) decreased by almost $77 \%$. The mean and standard deviation (mean $\pm \mathrm{SD}$ ) of $R_{\mathrm{k}}$ (core), $R_{\mathrm{pk}}$ (peaks) and $R_{\mathrm{vk}}$ (valleys) for PLA+ including the top face was $31.93 \pm 9.46 \mu \mathrm{m}, 3.71 \pm 1.69 \mu \mathrm{m}$ and $33.79 \pm$ $47.45 \mu \mathrm{m}$. When excluding the top face, the $R_{\mathrm{k}}$ (core) increased by almost $11 \%$, $R_{\mathrm{pk}}$ (peaks) increased by almost $13 \%$ and $R_{\mathrm{vk}}$ (valleys) decreased by almost $70 \%$. The mean and standard deviation (mean $\pm \mathrm{SD}$ ) of $R_{\mathrm{k}}$ (core), $R_{\mathrm{pk}}$ (peaks) and $R_{\mathrm{vk}}$ (valleys) for ABS including the top face was $123.20 \pm 34.42 \mu \mathrm{m}, 72.12 \pm 28.37 \mu \mathrm{m}$ and $134.72 \pm 65.60 \mu \mathrm{m}$. When excluding the top face, the $R_{\mathrm{k}}$ (core), $R_{\mathrm{pk}}$ (peaks) and $R_{\mathrm{vk}}$ (valleys) increased by almost $7 \%$. The mean and standard deviation (mean $\pm \mathrm{SD}$ ) of $R_{\mathrm{k}}$ (core), $R_{\mathrm{pk}}$ (peaks) and $R_{\mathrm{vk}}$ (valleys) for $\mathrm{ABS}+$ including the top face was $42.41 \pm 7.82 \mu \mathrm{m}, 11.36 \pm 6.22 \mu \mathrm{m}$ and $101.98 \pm 60.62 \mu \mathrm{m}$. When excluding the top face, the $R_{\mathrm{k}}$ (core) increased by almost $8 \%, R_{\mathrm{pk}}$ (peaks) increased by almost $18 \%$ and $R_{\mathrm{vk}}$ (valleys) decreased by almost $24 \%$.

It is precisely observed that PLA+ filament material exhibits an excellent surface behaviour compared to other filament materials due to its lower printing temperature, PLA+, when properly cooled, is less likely to deform or layer breaking problems (making it easier to print with) and can print sharper corners and features. It also shows that the top face for all filament materials exhibits irregularity surface distribution with high valleys compared to other faces (C1-C2, C2-C3, C3-C4, C4-C1).

Figure 15 shows the material ratio assessment $\left(M_{r 1} \& M_{r 2}\right)$ of PLA, PLA+, $\mathrm{ABS}$ and $\mathrm{ABS}+$, which are corresponding to the upper and lower limit position of the roughness core. Based on the data results obtained from Figure 15, the mean and standard deviation (mean $\pm \mathrm{SD}$ ) of $\mathrm{M}_{\mathrm{r} 1}$ (material portion 1) and $\mathrm{M}_{\mathrm{r} 2}$ (material portion 2) including the top face were $5.05 \% \pm 2.21 \%$ and $81.73 \% \pm$ $12.05 \%$ (for PLA), $2.60 \% \pm 0.69 \%$ and $82.31 \% \pm 11.69 \%$ (for PLA + ), $9.64 \% \pm$ $3.67 \%$ and $78.11 \% \pm 8.67 \%$ (for ABS), $6.20 \% \pm 2.38 \%$ and $83.37 \% \pm 12.32 \%$ (for $\mathrm{ABS}+$ ), respectively.

In general, $\mathrm{M}_{\mathrm{rl}}$ shows tiny material portion by less than $10 \%$ for all printed parts whereas $M_{r 2}$ shows large material portion by more than $90 \%$ for all printed parts. These results indicate that all FDM 3D printed parts with different thermoplastic filament materials exhibit approximately $\sim 10 \%$ flat peaks over roughly $\sim 90 \%$ steep valleys, which is consistent with the results obtained from skewness $\left(R_{\mathrm{sk}}, W_{\mathrm{sk}}\right.$ and $\left.P_{\mathrm{sk}}\right) 3^{\text {rd }}$ moment and the kurtosis $\left(R_{\mathrm{ku}}, W_{\mathrm{ku}}\right.$ and $\left.P_{\mathrm{ku}}\right) 4^{\text {th }}$ moment of all FDM $3 \mathrm{D}$ printed parts. The $\sim 10 \%$ flat peaks are varied with different thermoplastic filament materials starting from low to high material portion as follows PLA $+<\mathrm{PLA}<\mathrm{ABS}+<\mathrm{ABS}$. These findings include top and four identical side faces. The $\sim 90 \%$ steep valleys are varied with different thermoplastic filament materials starting from low to high material portion as follows ABS $<$ PLA $<\mathrm{PLA}+<\mathrm{ABS}+$. Another finding is that the top face of PLA, PLA+ and ABS exhibits the same pattern of $R_{\mathrm{vk}}$ (steep valleys) and then dropped dramatically at the other four faces (C1-C2, C2-C3, C3-C4, C4-C1), whereas ABS shows 


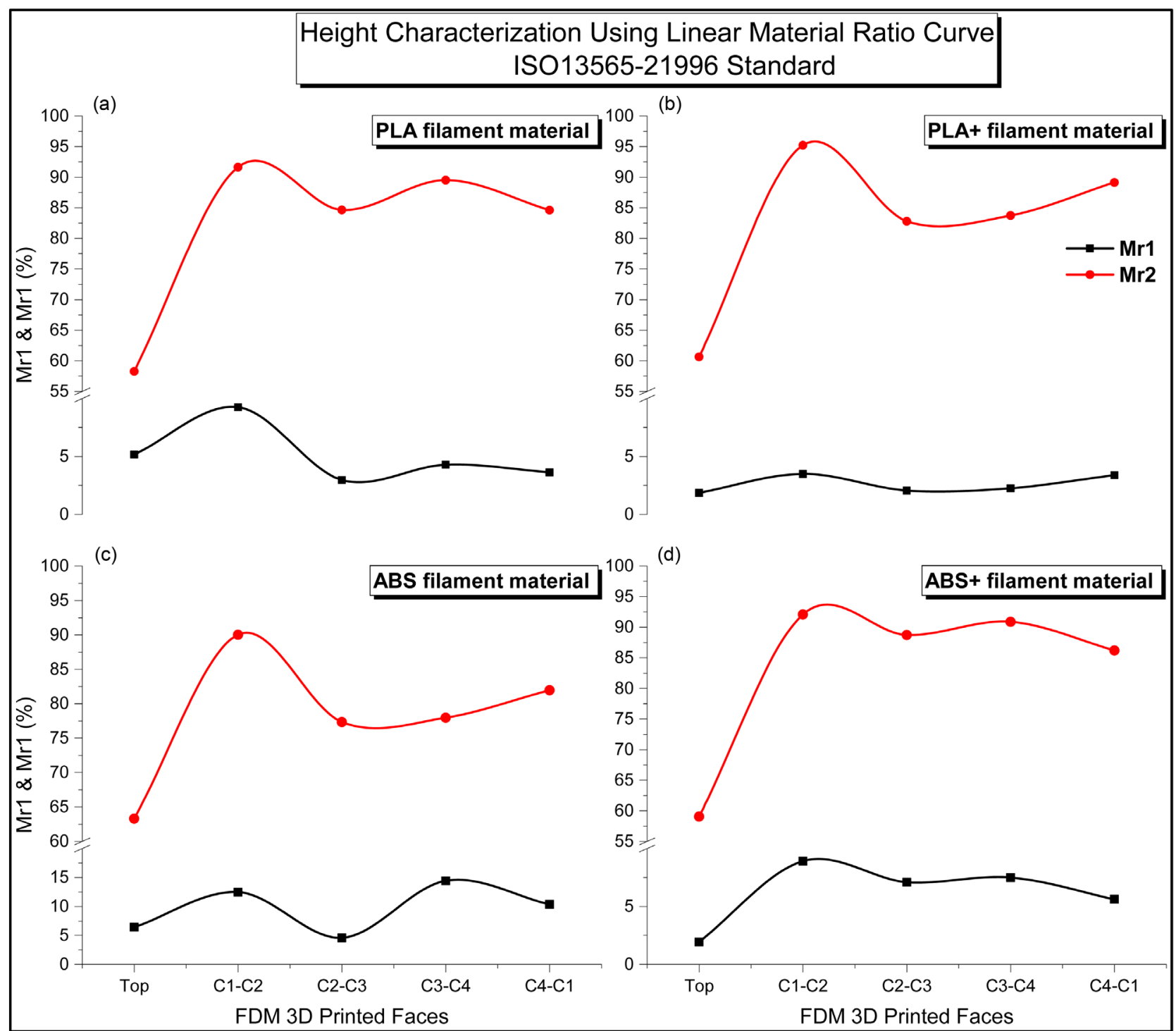

Figure 15. Material ratio assessment $\left(\mathrm{M}_{\mathrm{r} 1} \& \mathrm{M}_{\mathrm{r} 2}\right)$ of (a) PLA; (b) PLA+; (c) ABS and (d) ABS+.

irregularity surface behaviour distribution among the group of $R_{\mathrm{k}}$ (core), $R_{\mathrm{pk}}$ (peaks) and $R_{\mathrm{vk}}$ (valleys). It also shows that $R_{\mathrm{k}}$ (core) and $R_{\mathrm{pk}}$ (flat peaks) remain unchanged over four faces including the top face for PLA, PLA+ and ABS+.

\section{Conclusions}

This paper presents an experimental platform which is used to study the surface roughness quality of FDM $3 \mathrm{D}$ printed parts using different filament materials namely PLA, PLA+, ABS and ABS+ along with the dimensional accuracy in length, height and width of all printed parts. The surface roughness quality and dimensional accuracy of FDM 3D printed parts were analyzed, and the following conclusions were arrived at:

- Undesirable warping deformation and shape errors occur in the final rectangular printed parts due to heat shrinkage compared to the true value of 40 
$\mathrm{mm}(\mathrm{L}) \times 40 \mathrm{~mm}(\mathrm{~W}) \times 15 \mathrm{~mm}(\mathrm{H})$ ranging from less than $3 \%$ (for PLA and $\mathrm{PLA}+$ ) to $34.53 \%$ (for ABS and $\mathrm{ABS}+$ ).

- PLA, PLA+ and ABS+ show the same surface roughness, waviness and primary behaviour in the four faces $(\mathrm{C} 1-\mathrm{C} 2, \mathrm{C} 2-\mathrm{C} 3, \mathrm{C} 3-\mathrm{C} 4, \mathrm{C} 4-\mathrm{C} 1)$ where the top faces (middle) reach the high value of $R_{\mathrm{a}}, W_{\mathrm{a}}$ and $P_{\mathrm{a}}$, whereas ABS shows irregularity distribution in the surface roughness, waviness and primary for all four faces including the top face (middle) and there is no distinctive pattern to observe.

- PLA and PLA+ show an excellent surface profile ratio with almost constant deviation in $R_{\mathrm{q}} / R_{\mathrm{q}}, W_{\mathrm{q}} / W_{\mathrm{a}}$ and $P_{\mathrm{q}} / P_{\mathrm{a}}$. Whereas $\mathrm{ABS}$ and $\mathrm{ABS}+$ show unacceptable surface profile ratio with random variation in deviation in $R_{\mathrm{q}} / R_{\mathrm{q}}$, $W_{\mathrm{q}} / W_{\mathrm{a}}$ and $P_{\mathrm{q}} / P_{\mathrm{a}}$.

- The surface texture of the FDM 3D printed parts by PLA, PLA+ and ABS is characterized by small values of skewness $\left(R_{\mathrm{sk}}, W_{\mathrm{sk}}\right.$ and $\left.P_{\mathrm{sk}}\right)$ and kurtosis $\left(R_{\mathrm{ku}}\right.$, $W_{\mathrm{ku}}$ and $\left.P_{\mathrm{ku}}\right)$. However, ABS is characterized by large values of skewness $\left(R_{\mathrm{sk}}\right.$, $W_{\text {sk }}$ and $\left.P_{\text {sk }}\right)$ and kurtosis $\left(R_{\mathrm{ku}}, W_{\mathrm{ku}}\right.$ and $\left.P_{\mathrm{ku}}\right)$.

- The distribution of ABS printed sample is characterized by a significant fluctuation of changes in the value of $R_{\mathrm{k}}, R_{\mathrm{pk}}$ (flat peaks) and $R_{\mathrm{vk}}$ (steep valleys) parameters.

- At the top face (middle), the $R_{\mathrm{vk}}$ (steep valleys) for PLA, PLA+ and ABS+ exhibits very high values, while the $R_{\mathrm{vk}}$ (steep valleys) for ABS exhibits slightly less value.

- $\mathrm{M}_{\mathrm{r} 1}$ (material portion 1) shows tiny material portion by less than $10 \%$ whereas $\mathrm{M}_{\mathrm{r} 2}$ (material portion 2 ) shows considerable material portion by more than $90 \%$ for all printed parts.

To sum up, the authors believe the acquired data generated from this investigation will be helpful in such a way that they can be further employed in the development of the thermoplastic filament materials which can be used in the personal/desktop cost-effectives FDM 3D printers.

\section{Conflicts of Interest}

The authors have no conflicts of interest.

\section{Funding}

The authors received no financial support for the research and/or for the publication of this article.

\section{References}

[1] Tay, Y.W.D., et al. (2017) 3D Printing Trends in Building and Construction Industry: A Review. Virtual and Physical Prototyping, 12, 261-276. https://doi.org/10.1080/17452759.2017.1326724

[2] Hashemi Sanatgar, R., Campagne, C. and Nierstrasz, V. (2017) Investigation of the Adhesion Properties of Direct 3D Printing of Polymers and Nanocomposites on Textiles: Effect of FDM Printing Process Parameters. Applied Surface Science, 403, 
551-563. https://doi.org/10.1016/j.apsusc.2017.01.112

[3] Abdullah, A.M., et al. (2017) Mechanical and Physical Properties of Highly $\mathrm{ZrO}_{2} / \beta$ TCP Filled Polyamide 12 Prepared via Fused Deposition Modelling (FDM) 3D Printer for Potential Craniofacial Reconstruction Application. Materials Letters, 189, 307-309. https://doi.org/10.1016/j.matlet.2016.11.052

[4] Mohamed, O.A., Masood, S.H. and Bhowmik, J.L. (2016) Mathematical Modeling and FDM Process Parameters Optimization Using Response Surface Methodology Based on Q-Optimal Design. Applied Mathematical Modelling, 40, 10052-10073. https://doi.org/10.1016/j.apm.2016.06.055

[5] Williams, R.E., et al. (1996) Investigation of the Effect of Various Build Methods on the Performance of Rapid Prototyping (Stereolithography). Journal of Materials Processing Technology, 61, 173-178. https://doi.org/10.1016/0924-0136(96)02483-1

[6] Jin, Y.-A., et al. (2015) Quantitative Analysis of Surface Profile in Fused Deposition Modelling. Additive Manufacturing, 8, 142-148. https://doi.org/10.1016/j.addma.2015.10.001

[7] Galantucci, L.M., Lavecchia, F. and Percoco, G. (2009) Experimental Study Aiming to Enhance the Surface Finish of Fused Deposition Modeled Parts. CIRP Annals Manufacturing Technology, 58, 189-192. https://doi.org/10.1016/j.cirp.2009.03.071

[8] He, Y., Xue, G.-H. and Fu, J.-Z. (2014) Fabrication of Low Cost Soft Tissue ProsTheses with the Desktop 3D Printer. Journal name, 4, 6973.

[9] Gu, P. and Li, L. (2002) Fabrication of Biomedical Prototypes with Locally Controlled Properties Using FDM. CIRP Annals-Manufacturing Technology, 51, 181 184. https://doi.org/10.1016/S0007-8506(07)61495-4

[10] Centola, M., et al. (2010) Combining Electrospinning and Fused Deposition Modeling for the Fabrication of a Hybrid Vascular Graft. Biofabrication, 2, Article ID: 014102. https://doi.org/10.1088/1758-5082/2/1/014102

[11] Karamooz Ravari, M.R., et al. (2014) Numerical Investigation on Mechanical Properties of Cellular Lattice Structures Fabricated by Fused Deposition Modeling. International Journal of Mechanical Sciences, 88, 154-161. https://doi.org/10.1016/j.ijmecsci.2014.08.009

[12] Schantz, J.-T., et al. (2005) Osteogenic Differentiation of Mesenchymal Progenitor Cells in Computer Designed Fibrin-Polymer-Ceramic Scaffolds Manufactured by Fused Deposition Modeling. Journal of Materials Science: Materials in Medicine, 16, 807-819. https://doi.org/10.1016/j.scriptamat.2004.08.006

[13] Chen, Z., et al. (2005) Fabrication of Osteo-Structure Analogous Scaffolds via Fused Deposition Modeling. Scripta Materialia, 52, 157-161. https://doi.org/10.1016/j.scriptamat.2004.08.006

[14] Ahn, D., et al. (2009) Representation of Surface Roughness in Fused Deposition Modeling. Journal of Materials Processing Technology, 209, 5593-5600. https://doi.org/10.1016/j.jmatprotec.2009.05.016

[15] Carneiro, O.S., Silva, A.F. and Gomes, R. (2015) Fused Deposition Modeling with Polypropylene. Materials \& Design, 83, 768-776. https://doi.org/10.1016/j.matdes.2015.06.053

[16] Casavola, C., et al. (2016) Orthotropic Mechanical Properties of Fused Deposition Modelling Parts Described by Classical Laminate Theory. Materials \& Design, 90, 453-458. https://doi.org/10.1016/j.matdes.2015.11.009

[17] Smith, W.C. and Dean, R.W. (2013) Structural Characteristics of Fused Deposition Modeling Polycarbonate Material. Polymer Testing, 32, 1306-1312. 
https://doi.org/10.1016/j.polymertesting.2013.07.014

[18] Alsoufi, M.S. and Elsyeed, A.E. (2017) Warping Deformation of Desktop 3D Printed Parts Manufactured by Open Source Fused Deposition Modeling (FDM) System. International Journal of Mechanical and Mechatronics Engineering, 17, 716.

[19] Alsoufi, M.S. and Elsayed, A.E. (2017) How Surface Roughness Performance of Printed Parts Manufactured by Desktop FDM 3D Printer with PLA+ Is Influenced by Measuring Direction. American Journal of Mechanical Engineering, 5, 211-222.

[20] Rezayat, H., et al. (2015) Structure-Mechanical Property Relationship in Fused Deposition Modelling. Materials Science and Technology, 31, 895-903. https://doi.org/10.1179/1743284715Y.0000000010

[21] Nevin, H. and Mehrdad, H. (2014) Deposition Direction-Dependent Failure Criteria for Fused Deposition Modeling Polycarbonate. Rapid Prototyping Journal, 20, 221-227. https://doi.org/10.1108/RPJ-04-2013-0039

[22] Letcher, T. and Waytashek, M. (2014) Material Property Testing of 3D-Printed Specimen in PLA on an Entry-Level 3D Printer. Advanced Manufacturing, 2A, 1-8. https://doi.org/10.1115/IMECE2014-39379

[23] Bagsik, A. and Schöppner, V. (2011) Mechanical Properties of Fused Deposition Modeling Parts Manufactured with Ultem*9085. ANTEC, 2, 1294-1298.

[24] Zhong, W., et al. (2001) Short Fiber Reinforced Composites for Fused Deposition Modeling. Materials Science and Engineering: A, 301, 125-130.

https://doi.org/10.1016/S0921-5093(00)01810-4

[25] Mireles, J., et al. (2013) Development of a Fused Deposition Modeling System for Low Melting Temperature Metal Alloys. Journal of Electronic Packaging, 135, 011 008-1-011008-6. https://doi.org/10.1115/1.4007160

[26] Zein, I., et al. (2002) Fused Deposition Modeling of Novel Scaffold Architectures for Tissue Engineering Applications. Biomaterials, 23, 1169-1185. https://doi.org/10.1016/S0142-9612(01)00232-0

[27] Allahverdi, M., et al. (2001) Processing of Advanced Electroceramic Components by Fused Deposition Technique. Journal of the European Ceramic Society, 21, 1485 1490. https://doi.org/10.1016/S0955-2219(01)00047-4

[28] Masood, S.H. and Song, W.Q. (2004) Development of New Metal/Polymer Materials for Rapid Tooling Using Fused Deposition Modelling. Materials \& Design, 25, 587-594. https://doi.org/10.1016/j.matdes.2004.02.009

[29] Dong, W.P., Sullivan, P.J. and Stout, K.J. (1992) Comprehensive Study of Parameters for Characterizing Three-Dimensional Surface Topography I: Some Inherent Properties of Parameter Variation. Wear, 159, 161-171. https://doi.org/10.1016/0043-1648(92)90299-N

[30] Dong, W.P., Sullivan, P.J. and Stout, K.J. (1993) Comprehensive Study of Parameters for Characterizing Three-Dimensional Surface Topography II: Statistical Properties of Parameter Variation. Wear, 167, 9-21. https://doi.org/10.1016/0043-1648(93)90050-V

[31] Dong, W.P., Sullivan, P.J. and Stout, K.J. (1994) Comprehensive Study of Parameters for Characterising Three-Dimensional Surface Topography: III: Parameters for Characterising Amplitude and Some Functional Properties. Wear, 178, 29-43. https://doi.org/10.1016/0043-1648(94)90127-9

[32] Dong, W.P., Sullivan, P.J. and Stout, K.J. (1994) Comprehensive Study of Parameters for Characterising Three-Dimensional Surface Topography IV: Parameters for 
Characterising Spatial and Hybrid Properties. Wear, 178, 45-60. https://doi.org/10.1016/0043-1648(94)90128-7

[33] Thomas, T.R. (1981) Characterization of Surface Roughness. Precision Engineering, 3, 97-104. https://doi.org/10.1016/0141-6359(81)90043-X

[34] Whitehouse, D. (2002) 2-Identification and Separation of Surface Features. Surfaces and Their Measurement, 16-47. https://doi.org/10.1016/B978-190399601-0/50002-5

[35] Mordo, S., Popravko, V. and Barari, A. (2013) Study of the Effect of Coating Parameters and Substrates on 3D Surface Roughness in Diamond-Like-Carbon Coating Process. IFAC Proceedings Volumes, 46, 1861-1866. https://doi.org/10.3182/20130619-3-RU-3018.00585

[36] Alsoufi, M.S. and Bawazeer, T.M. (2015) Quantifying Assessment of Touch-Feel Perception: An Investigation Using Stylus Base Equipment and Self-Touch (Human Fingertip). Journal of Engineering and Architecture, 1, 1-16.

[37] Alsoufi, M.S. and Bawazeer, T.M. (2015) The Effect of Aggressive Biological Materials on a Painted Automotive Body Surface Roughness. American Journal of Nano Research and Applications, 3, 17-26.

[38] Suker, D.K., et al. (2016) Studying the Effect of Cutting Conditions in Turning Process on Surface Roughness for Different Materials. World Journal of Research and Review (WJRR), 2, 16-21.

[39] Alsoufi, M.S., et al. (2016) Experimental Study of Surface Roughness and MicroHardness Obtained by Cutting Carbon Steel with Abrasive WaterJet and Laser Beam Technologies. American Journal of Mechanical Engineering, 4, 173-181.

[40] Bawazeer, T.M., et al. (2016) Effect of Aqueous Extracts of Salvadora Persica "Miswak" on the Acid Eroded Enamel Surface at Nano-Mechanical Scale. Materials Sciences and Applications, 7, 754-771. https://doi.org/10.4236/msa.2016.711059

[41] Alsoufi, M.S., et al. (2016) Surface Roughness and Knoop Indentation MicroHardness Behavior of Aluminium Oxide $\left(\mathrm{Al}_{2} \mathrm{O}_{3}\right)$ and Polystyrene $\left(\mathrm{C}_{8} \mathrm{H}_{8}\right)$ n Materials. International Journal of Mechanical \& Mechatronics Engineering, 16, 43-49.

[42] Alsoufi, M.S., et al. (2017) Influence of Abrasive Waterjet Machining Parameters on the Surface Texture Quality of Carrara Marble. Journal of Surface Engineered Materials and Advanced Technology, 7, 25-37. https://doi.org/10.4236/jsemat.2017.72003

[43] Alsoufi, M.S., et al. (2017) Abrasive WaterJet Machining of Thick Carrara Marble: Cutting Performance vs. Profile, Lagging and WaterJet Angle Assessments. Materials Sciences and Applications, 8, 361-375. https://doi.org/10.4236/msa.2017.85025

[44] Alsoufi, M.S. (2011) A High Dynamic Response Micro-Tribometer MeasuringHead, in School of Engineering. University of Warwick, Coventry.

[45] Ferreira, R.T.L., et al. (2017) Experimental Characterization and Micrography of 3D Printed PLA and PLA Reinforced with Short Carbon Fibers. Composites Part B: Engineering, 124, 88-100. https://doi.org/10.1016/j.compositesb.2017.05.013

[46] Kumbhar, N.N. and Mulay, A.V. (2016) Finishing of Fused Deposition Modelling (FDM) Printed Parts by $\mathrm{CO}_{2}$ Laser. 6th International \& 27 th All India Manufacturing Technology, Design and Research Conference (AIMTDR-2016), Maharashtra, 63-67.

[47] Galantucci, L.M., et al. (2015) Analysis of Dimensional Performance for a 3D OpenSource Printer Based on Fused Deposition Modeling Technique. Procedia CIRP, 28, 82-87. https://doi.org/10.1016/j.procir.2015.04.014

[48] Kechagias, J., et al. (2014) Surface Roughness Optimization of Prototypes Produced 
by Polyjet Direct 3D Printing Technology. In: M.G. Karlaftis, N.D. Lagaros and M. Papadrakakis, Eds., OPT-i International Conference on Engineering and Applied Sciences Optimization 2014, Kos Island, 2877-2888.

[49] Jin, Y., Wan, Y. and Liu, Z. (2017) Surface Polish of PLA Parts in FDM Using Dichloromethane Vapour. MATEC Web Conf., 95, Article ID: 05001.

https://doi.org/10.1051/matecconf/20179505001

[50] Li, Y., et al. (2017) Cost, Sustainability and Surface Roughness Quality-A Comprehensive Analysis of Products Made with Personal 3D Printers. CIRP Journal of Manufacturing Science and Technology, 16, 1-11. https://doi.org/10.1016/j.cirpj.2016.10.001

[51] Hambali, R.H., Cheong, K.M. and Azizan, N. (2017) Analysis of the Influence of Chemical Treatment to the Strength and Surface Roughness of FDM. IOP Conference Series: Materials Science and Engineering, 210, Article ID: 012063. https://doi.org/10.1088/1757-899X/210/1/012063

[52] Gibson, I., Rosen, D. and Stucker, B. (2015) Additive Manufacturing Technologies: 3D Printing, Rapid Prototyping, and Direct Digital Manufacturing. Springer-Verlag, New York, XXI, 498. https://doi.org/10.1007/978-1-4939-2113-3

[53] Nuez, P.J., et al. (2015) Dimensional and Surface Texture Characterization in Fused Deposition Modelling (FDM) with ABS Plus. Procedia Engineering, 132, 856-863. https://doi.org/10.1016/j.proeng.2015.12.570

[54] esun. http://www.esunchina.net 